\title{
Ueber die Intoxicationsamblyopie.
}

\author{
Von \\ Dr. Groenouw, \\ Assistenzarzt an der $\mathrm{Kgl}$. Universitătsklinik für Augenkranke \\ zu Breslau.
}

Hierzu Taf. I-III, Fig. 1-36.

Seit der Anwendung des Augenspiegels für die ophthalmologische Diagnostik ist zwar der Begriff ,schwarzer Staar" verschwunden and hat sich in eine Menge einzelner Krankheiten aufgelöst, indessen ist ein ähnlicher vager Begriff, nämlich „Amblyopie ohne Befund", auch durch die Augenspiegeluntersuchung nicht aus der Welt geschafft worden. Erst durch die Anwendung einer genauen Gesichtsfeldmessung, welche zuerst Graefe in ausgedehnterer Weise diagnostisch verwerthete und Förster durch die Einführung des Perimeters in die practische Augenheilkunde weiter vervollkommnete, ist auch in dieses dunkle Gebiet Klarheit gekommen. Eine Gruppe von Krankheiten ist es vor allen, welche, obschon früher bereits bekannt, erst durch die genauere Erforschung der ihr eigenthümlichen Gesichtsfeldveränderungen eine exacte diagnostische und damit auch therapeutische Grundlage erhalten hat, nämlich die Intoxicationsamblyopien. Die überwiegende Mehrzahl derselben verdankt ihre Entstehung übermässigem Tabak - und Alkoholgenuss, während schädliche Einwirkungen anderer Sub- 
stanzen auf das Sehorgan nur spärlich zur Beobachtung kommen.

Die Tabaks- und Alcoholamblyopie, welche uns hier ausschliesslich beschäftigen soll, hat bereits eine grosse Literatur aufzuweisen. Als erster erwähnt Mackenzie (1832) den ïbermässigen Tabaksgenuss als Ursache für ernstere Sehstörungen, bält aber irrthümlicher Weise die Prognose dabei für sehr bedenklich, während Hutchinson ${ }^{1}$ ) an der Hand sorgfältiger statistischer Zusammenstellungen nachweist, dass die Prognose der Tabaksamblyopie bei Abstinenz ausserordentlich günstig sei. Sicbel ${ }^{2}$ ) kommt zu demselben Resultat.

Von Graefe beschreibt in seinen klinischen Vorträgen (Zehenders Monatsbl. III, S. 150) eine Form von Amblyopien mit normaler Gesichtsfeldperipherie und centralen Scotomen, welche sich allmählich entwickeln und meist in Heilung übergehen. Unter den ätiologischen Nomenten spielt übermässiger Genuss alcoholischer Getränke und frequentes Rauchen schwerer Cigarren eine wichtige Rolle. Den Sitz der Erkrankung verlegte er bei einem derartigen Falle (s. S. 213) mit Wahrscheinlichkeit in das cerebrale Ende der Sehnerven.

Eine genauere Beschreibung der Intoxicationsamblyopie ist in der 1867 in Zürich erschienenen Dissertation von Friedrich Erismann enthalten. Derselbe schildert das klinische Bild der Intoxicationsamblyopie, insbesondere die Allgemeinsymptome sehr gut. Er weiss, dass stets beide Augen befallen werden und die Sehschärfe höchstens bis auf Fingerzählen, nie bis auf quantitative Lichtempfindung oder gar absolute Amaurose herabgesetzt ist. Erismann will bei der genannten Erkrankung stets ophthalmoskopisch sichtbare Veränderungen des Sehnerven gefunden haben,

1) London Hosp. Reports 1864, Med.-Chir. Societ. Transact. 1867. Ophth. Hosp. Reports. 1871 und 1874.

2) Annales d'oculistique 1863. 
anfangs Hyperämie, später opakweisse Färbung der ganzen Papille oder ihrer temporalen Hälfte. Demgemäss erklärt er den Process als Hyperämie, chronische Entzündung und schliesslich Atrophie des Sehnervenstammes (retrobulbäre Neuritis). Er stützt diese Ansicht durch einen Sectionsbefund, wo sich fettige Degeneration der Nervenfasern und Verdickung des Bindegewebes im Sehnerven fand. Das ursächliche Moment findet Erismann in dem Missbrauche von Tabak, Alcohol oder von beiden gleichzeitig. Bei dem Gesichtsfeldbefunde führt er richtig an, dass die Aussengrenzen stets normal sind, dagegen fand er nie ein centrales Scotom.

Im nächsten Jahre (1868) hielt Professor Förster in der Schlesischen Gesellschaft für vaterländische Cultur zu Breslau einen Vortrag „Ueber den schädlichen Einfluss des Tabakrauchens auf das Sehorgan", in dem er ein typisches Krankheitsbild für diese Amblyopie entwirft. Etwas ausführlicher hat Förster seine Erfahrungen 1877 in dem Handbuche von Graefe und Saemisch, Band VII, S.201, dargelegt. Abgesehen von der ausführlichen Schilderung der Allgemeinsymptome bei der Intoxicationsamblyopie, als deren Ursache Förster den Tabak ansieht, während dem Alcohol nur eine secundäre, unterstützende Bedeutung zukommt, ist besonders die genaue Beschreibung des centralen Scotoms für roth und der charakteristischen Form desselben hervorzuheben. Förster betont ausdrücklich, dass man den Defect bei der Untersuchung mit kleinen, rothen Perimeterobjecten $(2-5 \mathrm{~mm}$ Seitenlänge) bei dieser Krankheit nie vermisst. Doch fand sich auch bei anderen Amblyopien ein ähnliches Scotom, allerdings dann fast stets mit einem absoluten Defect für weiss verbunden. Der Defect ist ein negativer, d. $h$. er wird von den Kranken nicht nach aussen hin projicirt, sie nehmen ihn nicht als einen dunklen Fleck im Gesichtsfelde wahr. Diese Defecte führt Förster in einer anderen Mittheilung (Zehender's Monatsbl, 
IX, S. 343) auf Erkrankungen in den leitenden Theilen der Netzhaut und des Sehnerven zurück, während die positiven Scotome, welche den Kranken namentlich bei schwacher Beleuchtung als dunkle Flecke zur Erscheinung kommen, auf einer Abstumpfung des Lichtsinnes in der Gegend der Macula lutea, also auf Chorioidealveränderungen, beruhen. Förster hat noch beobachtet, dass die Tabaksamblyopen bei gedämpfter Beleuchtung (in der Dämmerung) meist besser sehen, als im hellon Sonnenschein. Den Sitz des Leidens verlegt or bei der Intoxicationsamblyopie in die axialen Fasern des Opticus, nicht in das Centralorgan.

Leber behandelt 1869 in einer ausführlichen Arbeit (Arch. f. Ophth. XV,3) die Anomalien des Farbensinnes bei Krankheiten des Auges. Er wies u. A. nach, dass die Untersuchungen des Farbensinnes ein sehr bequemes und sicheres Mittel sei, centrale Gesichtsfelddefecte zu erkennen, und fand bei der Intoxicationsamblyopie als Erster mit dieser Untersuchungsmethode öfter ein centrales Scotom, das auf andere Weise nicht nachweisbar war. Mit dem Augenspiegel sah Leber so häufig eine Abblassung der temporalen Papillenhälfte bei derartigen Gesichtsfelddefecten, dass er die Scotome zuweilen aus dem ophthalmoskopischen Befunde diagnosticiren konnte. Die Ursache für den centralen Defect sucht er in einer Perineuritis des Sehnerven, indem er aus klinisehen Gründen annimmt, dass die das Netzhautcentrum versorgenden Fasern in der Peripherie des Sehnerven verlaufen, was durch spätere Untersuchungen für den orbitalen Theil des Nervus opticus auch anatomisch nachgewiesen worden ist. Als ätiologisches Moment der Intoxicationsamblyopie sieht Leber (Handbuch von Graefe und Saemisch, Band 5) Alcohol- und Tabaksmissbrauch an. Daguenet ${ }^{1}$ ), Reymond ${ }^{2}$ ) und Talko ${ }^{3}$ ) behandeln

T) Annal. d'ocul. 62 p. 136.

2) Liosservatore 1870, No. 20.

3) Warschauer Klinika. 1870, No. 14. 
1870 ebenfalls die Tabaks- und Alcoholamblyopie, ohne etwas neues $\mathrm{zu}$ bringen.

Landolt ${ }^{1}$ ) findet bei der Intoxicationsamblyopie ebenfalls einen centralen Defect für Farben, während Galezowski ${ }^{2}$ ) und Hirschler ${ }^{3}$ ) übermässigen Tabaks - und Alcoholgenuss zwar auch als Ursache für gewisse Formen von Amblyopie ansprechen, aber keine genauen Gesichtsfelduntersuchungen anfübren.

Eine eigenthümliche Ansicht über das Zustandekommen der Tabaksamblyopie stellt Ponti ${ }^{4}$ ) auf; derselbe will eine wahre Neuroretinitis infolge zu starken Tabaksgenusses bemerkt haben, welche ihren Grund angeblich in der durch das Nicotin bewirkten Paralyse der Gefässnerven hat. Das schwefelsaure Chinin soll nun die Gefässe verengern und dadurch Heilung der Tabaksamblyopie bewirken. Diese wunderbare Ansicht wird von Rava ${ }^{5}$ ) widerlegt, indem letzterer namentlich das Vorkommen der Neuroretinitis bei Tabaksamblyopie bezweifelt. Das Chinin in kleinen Dosen kann nach unserer Erfahrung bei der Tabaksamblyopie allerdings nützlich sein, aber nicht durch Verengerung der Netzhautgefässe und dadurch bewirkte Heilung der Neuroretinitis, sondern als Tonicum und Stomachicum.

Eingehende Würdigung findet die Intoxicationsamblyopie in dem Werke ron Schön $\left.{ }^{6}\right)$. Dieser konnte ein centrales Scotom fast ausnahmslos bei der Untersuchung mait einem rothen Objecte von $4 \mathrm{~mm}$ Seitenlänge nachweisen, während or den Defect bei der Prüfung mit grösseren $\mathrm{Ob}$ jecten stets vermisste. Es fiel ihm auf, dass trotz dieser Farbenscotome manchmal noch relativ hohe Sehschärfe
1) Annali d'Ottalm. 1871, S. 465.
2) Gaz. des hôp. 1871, S. 498.
$\left.{ }^{3}\right)$ Arch. f. Ophth. XVII, 1, S. 221.
4) Annali d'Ottalm. 1873. III. S. 107.
5) Ibidem, S. 92 .
6) Die Lehre vom Gesichtsfeld. Berlin 1874. S. 116. 
bestand. Schön erklärt das Scotom für den Ausdruck einer leichteren Ermüdbarkeit der Macula, welche sich bei Intoxicationsamblyopie in besonders hohem Maasse geltend mache. Das Netzhautbild des gelbweissen Fixationsknopfes am Perimeter soll durch Ermüdung der roth- und grünempfindenden Fasern den Defect gerade für rothe Objecte verursachen, auch die Ueberblendung soll an dem Zustandekommen dieses Ermuidungsscotomes Antheil haben. Diese mit den bisherigen Beobachtungen, insbesondere denen von Leber, in Widerspruch stehende Erklärung der Entstehung des centralen Defectes wurde schon im nächsten Jahre in der Dissertation ${ }^{1}$ ) von Treitel widerlegt. Letztere beschäftigt sich jedoch mehr mit der Sehnervenatrophie, als mit der Intoxicationsamblyopie, während diese erst in dem späteren Werke Treitels ${ }^{2}$ ) eingehender behandelt wird.

Unter dem Namen Amblyopia centralis beschreibt Krenchel ${ }^{3}$ ) die Intoxicationsamblyopie und bestätigt im wesentlichen die Angaben von Förster und Leber. Er fand bei der Untersuchung mit kleinen farbigen Objecten in allen Fällen ein centrales Scotom. Die Amblyopie war stets doppelseitig und befiel nur Männer. Krenchel sucht die Untersuchungsmethode dadurch zu verfeinern, dass er gleichzeitig je ein rothes Object nasal- und temporalwärts vom Fixationspunkt hält und fragt, ob ein Unterschied in der Farbe beider zu erkennen sei. Dass die Krankheit in allen Fällen durch Alcohol oder Tabaksmissbrauch bedingt sei, wird von Krenchel geleugnet. Das Wesen der Krankheit bleibt seiner Ansicht nach dunkel, da sich die gegebenen Erklärungen nicht mit den Thatsachen vertragen.

Hutchinson, der mehrfach über die Tabaksamblyopie geschrieben hat, stellt die Ansicht auf, dass gleichzeiti-

1) Königsberg 1875.

2) Ueber den Werth der Gesichtsfeldmessung mit Pigmenten etc. Berlin 1879.

3) Amblyopia centralis. Kopenhagen 1876. 
ger Alcoholgenuss die schädlichen Einwirkungen des Tabaks vermindere, eine Anschauung, welche nur noch Berry ${ }^{\mathbf{1}}$ ) verteidigt hat, während alle anderen Autoren das Gegentheil behaupten.

Die Frage, welcher Bestandtheil des Tabaks die Sehstörungen verschuldet, ist von Stoltenhoff ${ }^{2}$ ) in seiner Dissertation berührt worden; er kommt zu dem Resultate, dass dies das Nicotin sei.

Horner ${ }^{3}$ ) bestätigt die bisherigen Beobachtungen und beschreibt genauer die Abblassung der temporalen Papillenhälfte.

Hirschberg ${ }^{4}$ ) sucht eine Unterscheidung zwischen Tabaks- und Alcoholamblyopie in der Form des centralen Scotoms, welches bei Tabaksamblyopie paracentral sei, $\mathrm{d}$. h. sich zwischen Fixationspunkt und Mariotteschem Fleck erstrecke, während es bei Alcoholamblyopie pericentrisch erscheine, wiewohl der Fixirpunkt nicht gerade das mathematische Centrum des Defectes zu sein brauche. Bei der Alcoholamblyopie soll durch Vergrösserung des centralen Scotoms schliesslich vollständige Roth- und Grünblindheit eintreten, was bei der Tabaksamblyopie noch nicht beobachtet worden sei. Ausserdem giebt es Mischformen, welche durch gleichzeitige Einwirkung beider Gifte verursacht werden. Als vierte Form der Amblyopia centrica, wie er sie nennt, führt Hirschberg solche Fälle an, wo chronische Intoxicationen nicht mit Sicherheit nachzuweisen sind. Manchmal läge dann retrobulbäre Neuritis optica vor. Dieselben Ansichten sind in der unter Hirschberg's Leitung gearbeiteten Dissertation von Pötschke ${ }^{5}$ ) vertreten und

1) Ophth. Review. 1884. III, S. 101.

2) Ueber Amblyopia nicotiana. Dissertation. Bonn 1877.

3) Schweizer Correspondenzblatt VIII, 13, S. 396.

4) Deutsche Zeitschrift für klinische Medicin. 1878. No. 17 u. 18.

5) Beiträge zur Diagnostik und Prognostik der Amblyopien. Berlin 1878, und: Die Verwerthung der Gesichtsfeldprüfung für Diagnostik und Prognostik der Amblyopien. Dorpat 1886. 
weiter ausgeführt, insbesondere wird die klinische Zweitheilung in Intoxicationsamblyopie und retrobulbäre Neuritis festgehalten, obwohl einige Sectionsbefunde für die anatomische Gleichheit beider Processe zn sprechen scheinen.

Eine in der einschlägigen Literatur leider vollkommen unbeachtet gebliebene und doch sehr wichtige Arbeit über Intoxicationsamblyopie liefert $\mathrm{Baer}$ in seiner Abhandlung: „Ueber Gesichtsfeldmessung und deren allgemein diagnostische Bedeutung" (Volkmann's Sammlung No. 246). Er schildert ausfiuhrlich die Entstehung des Defectes für roth. Es tritt zunächst ein. Defect am Fixationspunkt und eine Vergrösserung des blinden Fleckes auf, beide vereinigen sich dann und bilden so das typische ovaläre Scotom, welches schliesslich nach oben und unten die Grenze der Rothempfindung erreichen kann, so dass das Gesichtsfeld für roth aus zwei getrennten Hälften, einer äusseren und einer inneren besteht. Baer hält diesen Defect für absolut charakteristisch für die durch Tabaksmissbrauch bedingte Amblyopie und bestreitet entschieden, dass alleiniger Abusus spirituosorum ohne gleichzeitigen Tabakgenuss ein derartiges Krankheitsbild erzeugen könne. Baer erklärt das Scotom aus einer mangelhaften Ernährung der scotomatösen Netzhautpartien infolge der durch das Nicotin bewirkten Contraction der Retinalgefässe, deren eigenthümliche Anordnung die Form des Scotoms bedinge. Herr Dr. Baer hatte die Güte, mir die von ihm benutzten Notizen und Krankengeschichten, meist Patienten unserer Poliklinik entstammend, zur Verfügung zu stellen, wofür ich ihm hiermit meinen besten Dank ausspreche.

In dem Werke von Treitel: „Ueber den Werth der Gesichtsfeldmessung mit Pigmenten für die Auffassung der Krankheiten des nervösen Sehapparates" (Berlin 1879) findet auf Seite 69 die Intoxicationsamblyopie eine ausführliche Besprechung. Treitel fand stets ein centrales Farbenscotom, die Form desselben soll öfter kreisrund als oval 
gewesen sein, die Aussengrenzen des Sehfeldes waren meist normal. Die Ursache dieser Erkrankung ist in lange Zeit fortgesetztem Alcoholgenuss, oft in Verbindung mit Tabakmissbrauch, selten in letzterem allein zu suchen. Die Hirschberg'sche Ansicht, dass ein pericentrales Scotom für Alcoholamblyopie, ein paracentrales für Tabakamblyopie charakteristisch sei, bestreitet Treitel entschieden. Prognostisch für ungünstig hält er den absoluten Verlust der Grünempfindung. Er will den Ausgang mehrerer Fälle von Intoxicationsamblyopie in Sehnervenatropie beobachtet haben, giebt aber selbst $\mathrm{zu}$, dass es sich dabei vielleicht auch um eine Complication der Intoxicationsamblyopie mit genuiner Atrophie gehandelt haben kann. Den Sitz der Erkrankuing verlegt er in den Sehnerven.

Ueber die Entstehung und Rückbildung des centralen Scotoms bei der Intoxicationsamblyopie stellt Nelson ${ }^{1}$ ) nach Beobachtungen an der v. Arltschen Klinik die Behauptung auf, dass dasselbe am Fixationspunkt beginne und dann auf den Mariotte'schen Fleck übergehe, bei der Rückbildung würde erst der Fixationspunkt frei. Letztere Anschauungsweise, der sich Hirschberg in seinem Referate uiber diese Arbeit ebenfalls anschliesst, steht mit unseren Beobachtungen im Widerspruche.

Eine feste anatomische Grundlage erhielt die Lehre von der Intoxicationsamblyopie durch die 1882 über den Verlauf der papillomacularen Fasern im Sehnerven veröffentlichten Arbeiten von Samelsohn ${ }^{2}$ ), Nettleship ${ }^{3}$ ) und Vossius ${ }^{4}$ ), deren Befunde später durch Bunge ${ }^{5}$ ) und Uhthoff ${ }^{6}$ ) bestätigt wurden. Die Ansicht Leber's, För-

1) Brit. med. Journ. II, S. 774 .

2) Arch. f. Ophthalm. 28, 1, S. 1.

3) Transact. of the Ophth. Soc. Vol. I.

4) Arch. f. Ophthalm, 28, 3, S. 201.

${ }^{5}$ Ueber Gesichtsfeld und Faserverlauf im optischen Leitungsapparat. Halle 1884.

6) Arch. f. Ophthalm. 32, 4, S. 95 und 33, 1, S. 257. 
ster's und v. Graefe's, dass das centrale Scotom auf einer Erkrankung des Sehnerven beruhe, wurde durch diese Untersuchung für vollkommen richtig erwiesen.

Das bis auf kleine Abweichungen bei allen Forschern gleiche Resultat über den Verlauf dieser Fasern ist folgendes. Das papillomaculare Bündel (Bunge), d. h. diejenige Nervenfasergruppe des Opticus, welche die Netzhautgegend zwischen Macula lutea und Papilla optica versorgt und sich in allen untersuchten Fällen mehr oder weniger erkrankt zeigte, liegt in der Sehnervenpapille in deren temporaler Hälfte in keilförmiger Anordnung. Der Keil ist mit seiner Spitze gegen die Centralgefässe bingerichtet und nimmt ungefaht 1/3 der Papillenoberfläche ein. Weiter centralwärts im Sehnerven ändert sich die Gestalt des Bündels folgendermaassen. Die Keilform bleibt auch im vordersten Theil des Opticus unmittelbar hinter dem Bulbus noch gewahrt, um weiter nach hinten allmählig in eine der Oberfäche des Nerven anliegende Sichel überzugehen. Die Concavität der Sichel ist den Centralgefässen zugewandt. Mit dem Eintritt der Gefässe in den Sehnervenstamm geht der Querschnitt des Herdes - nach Samelsohn plötzlich, nach den ïbrigen Beobachtern allmählig - in ein stehendes Oval über, das von der temporalen Seite des Sehnerven mehr nach dem Centrum desselben hinrückt. Erst im intracraniellen Theile des Nervus opticus hat das genannte Bündel eine rein centrale Lage, welche es im Chiasma, vielleicht schon im vorderen, jedenfalls aber im hinteren Theil desselben mit einer ausgesprochen dorsalen vertauscht, die Bündel beider Seiten rücken einander näher und sind gegenseitig durch Brücken verbunden. Im Tractus opticus liegt das Bündel wieder central sich mit seiner Basis nach oben innen gegen die Hirnsubstanz hin erstreckend, während es an den übrigen Seiten von einer breiten Schicht normaler Nervenfasern umgeben ist. Hiervon weicht die Angabe Bunge's insofern ab, als dieser das papillomaculare Bündel 
im hintersten Theile des Chiasmas in zwei Stränge, einen oberen und einen unteren gesondert fand, während Vossius diese Zweitheilung im Tractus opticus constatirte. Der pathologisch-anatomische Befund bestand in einer scharf umschriebenen interstitiellen Neuritis der erkrankten Partie, wobei sich innerhalb derselben oft noch eine grosse Zahl ron Nervenfasern erhalten zeigte, selten fand sich eine einfache Atrophie.

Samelsohn's Beobachtung stammt von einem Patienten, der anfangs nur ein centrales Farbenscotom zeigte, das später aber in einen absoluten Defect überging, sodass die zuerst auf Intoxicationsamblyopie gestellte Diagnose in retrobulbäre Neuritis modificirt wurde. Später traten deutliche Zeichen einer psychischen Störung ein, und Patient starb an einer Herzaffection. In diesem Falle erstreckten sich die Veränderungen im Sehnerven nur auf den zwischen Bulbus und Foramen opticum gelegenen Theil, weshalb Samelsohn als primäre Ursache der ganzen Affection einen Krankheitsprocess am Foramen opticum annimmt, welcher durch Compression des Sehnerven Circulationsstörungen und schliesslich eine descendirende Neuritis erzeugt hat. Samelsohn hält eine strenge Scheidung zwischen Intoxicationsamblyopie und retrobulbärer Neuritis für unrichtig. Er beschliesst seine Arbeit mit einer genauen Schilderung des klinischen Bildes der Intoxicationsamblyopie, woraus nur besonders hervorgehoben werden soll, dass Samelso hn bei der Untersuchung mittelst Massonscher Scheiben eine Herabsetzung des Lichtsinnes bei Intoxicationsamblyopie fand, sobald durch ein Röhrendiaphragma nur die centrale amblyopische Partie des Gesichtsfeldes untersucht wurde.

Der Kranke, dessen Section Vossius rornahm, hatte in seinen drei letzten Lebensjahren an einem centralen Scotome gelitten. Die Präparate Bunge's entstammen einem 45jährigen Tabetiker, dessen zwischen $F$ und $M^{1}$ ) sich er-

1) $\mathrm{F}=$ Fixationspunkt, $\mathrm{MI}=$ Mariotte'scher Fleck. 
streckendes Scotom während des Lebens genau untersucht worden war. Aus einem anderen Falle von Glaucom mit temporalem Gesichtsfeldreste, dessen Sehnerv Bunge ebenfalls untersuchen konnte, schliesst er, dass, wie bereits Leber angenommen hat (Arch, f. Ophth., XIV, 2, S. 216 und $\mathrm{XV}, 3$, S. 98), die die Peripherie der Netzhaut versorgenden Fasern im Opticus central, die in der Umgebung der Papille endenden aber an der Peripherie des Sehnervenstammes liegen. Bei dem centralen Scotome der Intoxieationsamblyopie hat Bunge meist einen Culminationspunkt gefunden, welcher zwischen Macula und Papille liegt und in welchem die Verdunkelung des rothen Objectes am stärksten ausgesprochen ist.

Die Sectionsergebnisse Uhthoff's stammen von sechs Alcoholikern; fünf derselben zeigten, soweit sich dies bei dem gestörten psychischem Zustande der Kranken constatiren liess, Sehstörungen mit centralem Scotom. Die pathologischen Veränderungen erstreckten sich in einem Falle nur 1-2 mm weit nach rückwärts von der Papille in den Sehnerven hinein, in einem zweiten erreichten sie das Foramen opticum, während sie sich in den übrigen Fällen weiter centralwärts ausgebreitet hatten. Alle Kranken zeigten während des Lebens eine deutliche Abblassung der temporalen Papillenhälfte oder richtiger eines keilförmigen Sectors derselben. Der sechste Fall bot während des Lebens keine Sehstörungen dar, bei demselben war die Verbreitung des krankhaften Processes im Sehnerven atypisch. Uhthoff untersuchte 1000 Patienten mit ausgesprochenem Alcoholismus ophthalmoscopisch. Als wichtigsten Befund führt er die Abblassung des temporalen Papillensectors an. Diese Veränderung fand sich bei $14 \%$ der Potatoren, wovon etwa die Hälfte gar keine Sehstörungen zeigte, während sie umgekehrt auch bei etwa $1 \%$ der übrigen Untersuchten, theils gesunder, dem Alcohol-Missbrauch nicht ergebener Männer, theils Geisteskranker, vorkam, es erscheint daher doch etwas 
bedenklich, diesen Befund für durchaus pathologisch hinzustellen. Sehstörungen ohne ophthalmoskopischen Befund bei Alcoholisten zeigten sich nur selten und zwar nur in frischen Fällen. Andere als die angeführten ophthalmoskopischen Veränderungen (Hyperämie oder Träbungen der Papille, Blutungen) zeigten sich nicht gerade häufig. Das Bild der typischen Intoxicationsamblyopie, das ausser bei den erwähnten Alcoholisten sich noch bei 100 Patienten der Schöler'schen Poliklinik fand, kommt fast ausschliesslich durch Alkohol- und Tabaksmissbrauch zustande. Als Ursache fand Uhthoff in $3 / 6$ aller Fälle übermässigen Alcoholgenuss, in $1 / 6$ Tabaksmissbrauch und in $2 / 6$ gleichzeitige Einwirkung beider Substanzen. Die übrigen ursächlichen Momente, Blei, Schwefelkohlenstoff und Diabetes mellitus kommen weniger in Betracht und erzeugen meist mehr der retrobulbären Neuritis nahestehende Erscheinungen. Uhthoff fand bei Intoxicationsamblyopie stets ein centrales Farbenscotom, einmal allerdings in einem ganz frischen Falle nur auf dem einen Auge. Der Defect besteht meist nur für roth und grün, selten für blau, sehr selten ist ein kleiner Theil des Defectes absolut. Zwei Fälle, welche roth und grün überhaupt nicht mehr erkannten, wurden vollständig geheilt, die Roth- und Grünempfindung kehrte wieder. Es ist also deren Verlust prognostisch durchaus nicht immer als ungünstig anzusehen. Die Aussengrenzen des Gesichtsfeldes sind bis auf wenige Fälle normal, einmal beruhte eine derartige concentrische Verengerung wahrscheinlich auf Anaesthesia retinae. Die Hirschberg'sche Ansicht, dass ein pericentrales Scotom für Alcoholamblyopie, ein paracentrales für Tabaksamblyopie charakteristisch sei, konnte Uhthoff nicht bestätigen. Ein Kranker zeigte, je nachdem er mit der Macula oder einem Seitentheile der Netzhaut fixirte, bald ein peri-, bald ein paracentrales Scotom. Das klinische Bild der retrobulbären Neuritis unterscheidet sich von dem der Intoxicationsam- 
blyopie durch die Ausdebnung und die Art des Scotoms, nur sehr wenige Fälle von Intoxicationsamblyopie gleichen in ihrem Gesichtsfeldbefunde der Neuritis retrobulbaris und. umgekehrt. Uhthoff hält daher mit Recht beide Affectionen trotz des anscheinend gleichen anatomischen Befundes für verschiedene Krankheiten.

Ein früherer Gegner der reinen Tabaksamblyopie, Rampoldi'), welcher an das Bestehen einer allein auf Tabaksmissbrauch, ohne gleichzeitigen Alcoholgenuss beruhenden Amblyopie nicht glaubte, hat sich von derem häufigen Vorkommen uberzeugt. Er hält für das Zustandekommen derselben einen allgemeinen Schwächezustand des Organismus, speciell Störungen in den Verdauungsorganen, für nothwendig, ein Umstand, auf den schon Förster aufmerksam gemacht hat. Nettleship ${ }^{2}$ ) hält den Tabak für das schädliche Agens der Intoxicationsamblyopie und bestreitet das Bestehen einer reinen Alcoholamblyopie vollkommen.

Eine interessante Selbstbeobachtung über Tabaksamblyopie theilt Filehne ${ }^{3}$ ) mit. Aus derselben ist besonders hervorzuheben, das plötzliche Auftreten der Affection inmitten voller Gesundheit, und die trotz vollkommener $\mathrm{Ab}$ stinenz noch vier Wochen lang andauernde Verschlimmerung der Erkrankung. Die erstere Beobachtung lässt sich mit den bisherigen Erfahrungen vielleicht insofern vereinigen, als einem so ausgezeichneten Beobachter wie Filehne die unbedeutenden Anfangssymptome der Tabaksamblyopie wohl auffallen mögen, an der überwiegenden Mehrzahl unserer oft recht wenig intelligenten Patienten aber unbeachtet vorübergehen. Filehne tritt für den centralen Ursprung der Tabaksamblyopie ein, da er einerseits innerhalb der defecten Gesichtsfeldpartie eine fortwährend wechselnde

1) Annali d'Ottalm. XIV, S. 113.

2) Ophth. Review. 1887. S. 227 und Brit. med. Journ. II, S. 21.

3) Arch. f. Ophthalm. 31, 2, S. 1 . 
rothe und grüne Marmorirung wahrnahm, andererseits aber auf dem linken Auge ein kleines dem blinden Flecke des rechten Auges identisches Scotom beobachtete. Das Auftreten eines derartigen Defectes ist jedenfalls sehr selten; denn ich konnte denselben trotz wiederholter daraufhingerichteter Untersuchungen bei keinem meiner Patienten entdecken.

\section{Das klinische Bild der Intoxicationsamblyopie.}

Nach der kurzen Uebersicht über die Lehre von der Intoxicationsamblyopie soll zunächst eine kurze Schilderung der Allgemeinsymptome bei diesem Krankheitsbilde Platz finden, ehe das wichtigste Kennzeichen, die Gesichtsfeldveränderung, einer eingehenden Betrachtung unterzogen wird. Die Allgemeinsymptome sollen nur kurz erwähnt werden, da sie bereits von anderen, insbesondere von Förster, vortrefflich beschrieben worden sind.

Es erscheint nicht überflïssig zu bemerken, dass zwischen Intoxicationsamblyopie und retrobulbärer Neuritis unterschieden werden muss, da beide Krankbeiten klinisch unbedingt auseinander zu halten sind, obwohl man anatotomisch die Intoxicationsamblyopie als eine besondere Form der retrobulbären Neuritis ansehen kann. Unter dem Namen retrobulbäre Neuritis werden eine Anzahl verschiedener Krankheiten zusammengefasst. Für die hier in Betracht kommende Form derselben, welche mit einem centralen Gesichtsfelddefecte einhergeht und meist mit Sehnervenatrophie endet, ist die von Förster eingeführte Bezeichnung ,axiale" Neuritis beibehalten worden, wenn dieser Name auch streng genommen nur für den hinteren Theil des Sehnerven, wo das Papillomacularbündel axial liegt, vollkommen zutreffend ist. Diese Affection deckt sich mit dem von Leber als chronische retro ulbäre Neuritis geschilderten Krankheitsbilde. 
In den typischen Fällen von Intoxicationsamblyopie handelt es sich um Männer in den mittleren Jahren, welche stark rauchen, daneben auch meist dem Genusse geistiger Getränke ergeben sind. Das Allgemeinbefinden ist gestört, Appetitlosigkeit, Agrypnie, träger Stuhlgang, Verminderung des Geschlechtstriebes und ein Gefühl von Mattigkeit und Abgeschlagenheit pflegen selten zu fehlen. Die Sehschärfe ist auf beiden Augen oft beträchtlich herabgesetzt, manchmal werden nur Finger in einigen Metern Entfernung gezählt, eine vollkommene Erblindung ist niemals vorhanden. Das Gesichtsfeld zeigt einen zwischen $\mathrm{F}$ und $\mathrm{M}$ gelegenen centralen eiförmigen Defect für roth bei intacten Aussengrenzen. Helles Licht, insbesondere Sonnenschein, wird von den Kranken sehr störend empfunden, bei gedämpfter Beleuchtung ist die Sehschärfe wenigstens relativ, manchmal auch absolut besser. Der Lichtsinn mit dem Förster'schen Photometer gemessen ist nicht herabgesetzt. Der Augenspiegel ergiebt ausser einer Abblassung des temporalen Papillenquadranten nichts abnormes. Entsagen diese Kranken dem Tabak- und Alcoholgenusse vollständig, so ändert sich das Bild sehr bald. Der Appetit kehrt wieder, die Patienten schlafen besser, sie fühlen sich elastisch und frisch wie seit Jahren nicht mehr, nur der Stuhlgang ist meist retardirt und muss durch Abführmittel hervorgebracht werden. Etwas später hebt sich die Sehschärfe allmälig und der centrale Defect für roth wird kleiner, um schliesslich vollkommen zu verschwinden. Nach einigen Wochen sind die Kranken gewöhnlich vollkommen hergestellt und können sich ohne Schaden wiederum einem wenn auch nur sehr mässigen Tabaks- und Alcoholgenusse ergeben.

Einige Punkte dieses Krankheitsbildes sollen nun genauer erörtert werden. Als Grundlage für die folgenden Untersuchungen diente das Material unserer Klinik und Poliklinik in den letzten 16 Jahren. Die Notizen und Gesichtsfelder stammen von den verschiedensten Untersuchern. 
Die Zahl der benutzten Krankengeschichten beträgt 185 mit ïber 400 Gesichtsfeldtafeln, doch werden nicht alle Kranken in jeder Rubrik vollzählig figuriren, da bei einzelnen derselben Notizen über den einen oder anderen Punkt fehlen.

Alter. Das Alter der Kranken schwankt nach Förster zwischen 26 und 74 Jahren, nach meinen Beobachtungen zwischen 25 und 68 Jahren. Unter 178 Patienten, sämmtlich Männer, standen im Alter von

\begin{tabular}{llll}
$25-29$ & Jahren & \multicolumn{2}{c}{6 Kranke } \\
$30-39$ & & 53 & \\
$40-49$ & $\prime$ & 71 & $"$ \\
$50-59$ & $\prime$ & 33 & $"$ \\
$60-68$ &, & 15 &
\end{tabular}

Die Krankheit ist also vor dem 30 . Jahre selten, steigt in ihrer Häufigkeit jenseits desselben rasch an, um zwischen 40 und 50 Jahren ihren Höhepunkt zu erreichen und wieder langsam abzufallen ${ }^{1}$ ). Alle Kranken unter 30 Jahren waren sehr starke Raucher und fast durchweg auch Trinker. Der jüngste Patient, ein 25 jähriger Droschkenkutscher (Fall 5) rauchte täglich 12 Cigarren, trank Schnaps und schlief sehr wenig, manche Nacht gar nicht. Ein 28jähriger Schuhmacher rauchte weniger, kaute aber Tabak und schlief nur etwa 4 Stunden in jeder Nacht. Es ist also bei allen jüngeren Kranken das Zusammentreffen eines abnorm hohen Tabaksconsumes mit noch anderen ungünstigen Momenten wie Alcoholmissbrauch, Appetit- und Schlafmangel, letztere beiden oft durch den Nicotingenuss selbst veranlasst, für die Entstehung einer Intoxicationsamblyopie erforderlich. Aeltere Personen dagegen sind gegen übermässigen Tabaksgenuss weniger widerstandsfähig.

1) Es sind hier nur die Tabaksamblyopen der verschiedenen Altersstufen unter einander verglichen worden, ein Vergleich derselben mit den gleichaltrigen übrigen Patienten ist nur schwer durchführbar.

v. Graefe's Archiv finr Ophthalmologie. XXXVur. 1. 
Beruf. Ordnet man die Kranken nach ihrer Beschäftigung, so ergeben sich einige ganz interessante Resultate. Es werden nämlich vorwiegend diejenigen Personen, welchen es ihr Beruf gestattet, den ganzen Tag über die Pfeife oder Cigarre nicht ausgehen zu lassen - denn der Tabak und nicht der Alcohol ist das wichtigste ätiologische Moment - - von der Intoxicationsamblyopie befallen. Man muss hierbei noch in Betracht ziehen, dass die vorliegende Statistik ausschliesslich ron poliklinischen, also bis auf wenige Ausnahmen den niederen und mittleren Stäuden angehörigen Kranken herstawmt, daher sind z. B. Landgeistliche und Gutsbesitzer, welche ein beträchtliches Contingent zur Intoxicationsamblyopie stellen, hier nur spärlich vertreten. Um einen Vergleich mit den unter den übrigen Kranken unserer Klinik und Poliklinik vertretenen Berufsarten zu haben, ist die Zahl der demselben Berufe angehörigen männlichen Patienten, welche in einem Jahre in der stationären Klinik aufgenommen waren, nach dem klinischen Jahrbuche ${ }^{1}$ ) in Klammern hinzugefügt. Die Zahl der letzteren beträgt nach Abzug von 28 Kindern und 4 Berufslosen zufällig ebenfalls 185, wie die Anzabl unserer Tabaksamblyopen. Besonders stark vertreten sind unter den Tabaksamblyopen einzelne Berufsklassen, so 14 Kaufleute (gegenüber 7 in der stationären Klinik verpflegten), 21 im Landverkehr beschäftigte Personen (gegenüber 12), darunter 10 Kutscher, 9 Bahnbeamte, 2 Briefträger; ferner 4 Schiffer (0), 10 Gastwirthe und Restaurateure (6), $21 \mathrm{Be}-$ amte jeder Art (12), darunter 1 Wachtmeister, 7 Steuerbeamte, 6 Lehrer, 1 Geistlicher. Forst- und Landwirthschaft sowie Gärtnerei stellen 21 Vertreter (22). Handwerker und Industriearbeiter sind 72 vertreten (84), darunter 12 Tischler und Holzarbeiter (3), 9 Schubmacher (5), 10 Maurer und Bauhandwerker (18), aber nur 1 Tabakarbeiter, während

1) Klinisches Jahrbuch, herausgeg. von A. Guttstadt. Berlin 1889 , S. 444. 
Müller, Buchbinder, Musiker, Berg- und Hüttenarbeiter gar nicht vertreten sind, letzteres lauter Berufsarten, welche ein Rauchen während der Arbeit nicht zulassen. Endlich sind noch 22 sogenannte Arbeiter (30), unter diesen 6 Haushälter, vorhanden. Ein Theil dieser "Arbeiter" führt seinen Namen wie lucus a non lucendo, indem es sich um arbeitsschene, dem Trunke ergebene Personen handelt. Doch sind es im Allgemeinen durchaus nicht nur Säufer und verkommene Individuen, welche von der Intoxicationsamblyopie heimgesucht werden, sondern es finden sich auch fleissige und nïchterne Männer darunter, welche durchaus nicht trinken, dagegen aber den ganzen Tag über die Pfeife und Cigarre nicht ausgehen lassen.

Aetiologie. Die angeführte Statistik kann nur einen nebensächlichen Beitrag zur Aetiologie der Intoxicationsamblyopie abgeben, viel besser werden wir den Ursachen dieser Krankheit näher kommen, wenn wir uns von einigen aufrichtigen und glaubwürdigen Kranken ihre Lebensgewohnheiten genau schildern lassen. Man darf dabei freilich nicht vergessen, dass uns eine grosse Zahl der hierhergehörigen Patienten absichtlich, theilweise wohl aus falschem Schamgefühl, hintergeht und das täglich genossene Schnapsund Tabaksquantum viel $\mathrm{zu}$ niedrig angiebt, wovon man sich später manchmal auf Grund des Eingeständnisses der Patienten selbst oder ihrer Angehörigen überzeugen kann. Einige Kranke sind sich auch darüber nicht klar, dass sie sehr stark rauchen, sie wissen nur, dass sie allwöchentlich eill Päckchon Tabak im Preise von so und so viel Pfennigen consumiren, beim Nachwiegen desselben stellt sich dann nicht selten heraus, dass das Päckchen $1 / 2$ Pfund oder mehr wiegt.

Das hauptsächlichste ätiologische Moment für die in Rede stehende Amblyopie ist der Tabak, dem Alcohol kommt meist nur eine unterstuitzende Wirkung zu. Es geht dies daraus hervor, dass wohl eine Anzahl Patienten mit der 
genannten Affection vorkommen, welche stark rauchen, dem Alcoholgenusse aber, wie sich manchmal mit Sicherheit feststellen lässt, gar nicht ergeben sind, z. B. Landgeistliche, während umgekehrt bei gewohnheitsmässigen Schnapssäufern, welche nicht rauchen, dasselbe Krankheitsbild von uns nicht sicher constatirt werden konnte. Dass durch vollkommene Abstinenz von alcoholischen Getränken bei fortgesetztem Tabaksgenuss die Amblyopie nicht verschwindet, beweist ein Fall unserer Beobachtung.

Der 42 jährige Schlossermeister $\mathrm{v}$. K. giebt an, seit seinem 15. Lebensjahre täglich bis 18 Cigarren oder 100 gr. Rippentabak aus der Pfeife geraucht und nebenbei bis 1 Liter Schnaps getrunken zu haben. Vor 4 Monaten bemerkte er eine Verschlechterung des Sehens und suchte einen Arzt auf, der ihm den Alcoholgenuss verbot, das Rauchen aber weiter gestattete. Infolgedessen will der Kranke seit 3 Monaten nur noch Thee und einfaches Bier getrunken, dagegen weiter geraucht haben, trotzdem hat die Sehschärfe noch mehr abgenommen. Gegenwärtig (10. December 1889) findet sich im Gesichtsfelde der typische Defect für roth, und die Sehschärfe ist auf dem rechten Auge auf das Zählen der Finger in 12', links in '5' beschränkt, mit $+6^{\prime \prime}$ wird rechts Sn IV, links Sn VII $1 / 2$ mühsam erkannt. Patient wurde vollkommener Abstinenz unterworfen, unter der sich das Allgemeinbefinden, namentlich die Agrypnie besserte, doch verliess er leider schon nach 3 Tagen die Klinik. Die Probe auf das Exempel, die Heilung durch Tabaksabstinenz, konnte trotzdem geliefert werden. Briefliche Nachforschungen bei der Frau des Patienten ergaben nämlich, dass derselbe nach 3 monatlicher Tabaksabstinenz wieder gat gesehen und auch in weiter Entfernung Personen erkannt haben soll. Trotzdem er jetzt wieder ebensoviel wie früher rauchte, soll er sich der erlangten Sehkraft doch bis zu seinem 1 Jahr später erfolgten Tode unvermindert weiter erfreut haben.

Unter allen unseren Patienten finden sich nur zwei Fälle, welche als reine Alcoholamblyopie angesehen werden können. Dieselben betreffen beide dem gewohnheitsmässigen Schnapsgenusse ergebene Frauen, zeigen jedoch mehr das Bild der axialen retrobulbären Neuritis, als das der Intoxicationsamblyopie. 
Die 54 Jahre alte Müllersfrau Ernestine D. liess sich am 10. Februar 1891 wegen einer seit Weihnachten bestehenden allmäligen Verschlechterung des Sehvermögens in die Klinik aufnehmen. Die Augen zeigten ausser einem mässigen Bindehautcatarrh nur eine geringe Abblassung der temporalen Papillenhälften. S betrug nur $2 \%{ }_{200}$ und mit $+10^{\prime \prime}$ wurde Sn II kl. erkannt. Am Förster'schen Photometer wurden nach 10 Minuten Aufenthalt im absolut finsteren Zimmer bei einer Beleuchtungsöfinung von $\frac{(3 \mathrm{~mm})^{2}}{2}$ alle Striche erkannt.

Das Gesichtsfeld zeigte normale Aussengrenzen für weiss und roth. Bei den ersten Untersuchungen wurde allerdings eine mässige concentrische Gesichtsfeldverengerung für weisse $0 \mathrm{~b}$ jecte angegeben, bei den späteren wenige Tage nachher erfolgten Untersuchungen aber nicht mehr, so dass die erste Angabe wohl nur auf ungenaue Angaben zu beziehen ist. Ferner fand sich auf beiden Augen ein centraler Gesichtsfelddefect, der sich von $F$ aus nach allen Richtungen hin $2-4^{0}$ weit erstreckte, für weisse, rothe und grüne Quadrate von $5 \mathrm{~mm}$ Seitenlänge. Die Grösse des Defectes für weisse und farbige Objecte zeigte vur einen geringen Unterschied. Urin frei von Zucker und Eiweiss, keine Symptome von Lues nachzuweisen, am Nervensysteme nichts pathologisches, dagegen gab P. zu, sehr stark Schnaps getrunken zu haben, was durch ihren Habitus durchaus bestätigt wurde. Dem Tabaksgenusse war die Kranke in keiner Form ergeben gewesen. Unter vollkommener Abstinenz hob sich die Sehschärfe sehr bald, der centrale Defect wurde kleiner und verschwand schliesslich ganz. Am 12. März 1891 konnte P. als geheilt entlassen werden. S betrug für jedes Auge $20 / 30$ und mit $+10^{\prime \prime}$ wurde Sn I $1 / 2$ gelesen. Das Gesichtsfeld zeigte normale Aussengrenzen für weiss, roth und grün; ein centraler Defect war selbst für kleine weisse, rothe und grüne Quadrate von $2 \mathrm{~mm}$ Seitenlänge nicht nachweisbar. Nur erschienen die rothen und grünen Objecte an $F$ etwas dunkler als unmittelbar nach aussen oder innen davon.

Der zweite Fall betrifft die 32 jährige Schuhmacherfrau Susanne G. Dieselbe stellte sich am 2. April 1891 wegen einer seit dem Herbste des vergangenen Jabres bestehenden, progressiven Abnahme der Sehschärfe vor. Es wurden mit jedem Auge nur noch Finger in $4 \mathrm{~m}$ gezählt und mit +6 "Buchstaben von Sn X erkannt. Der Augenspiegel zeigte sehr blasse Pap. opt., deren Aussehen den Verdacht einer beginnenden 
Sehnervenatrophie nahe legte. Das Gesichtsfeld zeigte bei normalen Aussengrenzen für weiss auf beiden Augen einen centralen Defect für roth $\left(5 \mathrm{~mm}^{2}\right)$, der nach innen von $\mathrm{F} 4^{0}$, nach aussen $16^{\circ}$ weit reichte und sich erheblich weiter nach oben und unten hin erstreckte, als der für die Intoxicationsamblyopie characteristische ovale Defect zwisehen $F$ und M. Ein Theil des Scotoms in einer Ausdehnung von $2-6^{\circ}$ um $F$ herum war absolut defect. Aetiologiseh konnte nur ein starker Alcoholconsum (1 Liter pro Tag) eruirt werden. Der Patientin wurde Abstinenz anempfohlen, doch verschwand sie bereits nach wenigen Tagen wieder aus der Behandlung, ohne dass inzwischen eine Veränderung des Zustandes eingetreten war. Ob es sich in diesem Falle um Alcoholamblyopie oder Sehnervenatrophie gehandelt hat, muss dahingesteilt bleiben.

Diese beiden Fälle sind die einzigen, in welchen für das geschilderte Krankheitsbild nur Alcoholmissbrauch ohne gleichzeitigen Tabaksgenuss verantwortlich gemacht werden kann. Nach den Beobachtungen Uhthoff's ist an dem Vorkommen schwererer Erkrankungen des Sehorganes bei gewohnheitsmässigen Schnapstrinkern nicht zu zweifeln. Indessen kommen derartige Fälle wahrscheinlich den Ophthalmologen weniger zu Gesicht, indem der moralisch rerkommene Säufer eher dem Delirium oder anderen schweren Leiden verfällt, bevor er wegen seiner Amblyopie einen Augenarzt aufsucht. Unter allen unseren Patienten mit Intoxicationsamblyopie, abgeseben von den erwähnten zwei Frauen, war keiner zu finden, bei welchem Tabaksmissbrauch vollkommen auszuschliessen gewesen wäre. Es ist daher für die Intoxicationsamblyopie, wenigstens bei unseren poliklinischen Patienten, der übermässige Tabaksgenuss als das wichtigste ätiologische Moment anzusehen, obwohl in vielen Fällen auch Alcoholmissbrauch vorlag.

Damit soll aber weder die Existenz der reinen Alcoholamblyopie nuch der Einfluss des gleichzeitigen Alcoholmissbrauches auf das Krankheitsbild bestritten werden. Vielmehr wird bei gleichzeitigem starken Consum alcoholischer Getränke schon eine geringere Tabaksmenge genügen, das 
Bild der Intoxicationsamblyopie hervorzurufen, als beim Fehlen dieses Momentes. Es wirkt der Alcoholmissbrauch eben als schwächendes Moment ähnlich wie Kummer, Schlafmangel und Appetitlosigkeit (z. B. Fall 11,) und bedingt somit den Ausbruch der Amblyopie, welcher bei sonstigem vollen Wohlbefinden vielleicht gar nicht, jedenfalls aber erst später erfolgt wäre. Möglicher Weise prägt gleichzeitiger Alcoholgenuss dem Krankheitsbilde einen mehr acuten Character auf, wenigstens trat bei manchen beiden Gewohnheiten fröhnenden Kranken unter vollkommener $\mathrm{Ab}$ stinenz eine auffallend rasche Besserung innerhalb weniger Tage ein (Scotoma fugax Hirschberg's), während bei anderen Kranken, die zwar leidenschaftliche Raucher, aber keine Trinker waren, bis zur eintretenden Besserung und vollen Heilung Monate vergingen. Allerdings handelte es sich in den letzteren Fällen fast immer um besser situirte Patienten, welche nur ambulant behandelt wurden, so dass der Verdacht, es sei nicht volle Abstinenz geübt worden, sehr nahe lag, ja einmal bestätigt werden konnte.

Die täglich genossene Tabaksmenge, welche zur Erzeugung der Tabaksamblyopie nothwendig ist, unterliegt sehr starken Schwankungen. J. Sichel nimmt als tägliches noch unschädliches Maximum $20 \mathrm{~g}$, Hutchinson $15 \mathrm{~g}$ allerdings schlechten und demmach stärker nicotinhaltigen Tabak an, während Hirschberg $30 \mathrm{~g}$ für die tägliche Maximaldosis betrachtet. Das erlaubte Tabaksquantum ist entschieden grossen individuellen Schwankungen unterworfen, indem manche Personen ungestraft sehr bedeutende Quantitäten vertragen, während andere bei viel geringerem Tabaksconsum einer Amblyopie verfallen. Wie schon erwähnt, begünstigen schwächende Momente und daher auch reichlicher Alcoholgenuss den Ausbruch der Krankheit und verringern demnach das gestattete Tabaksquantum. Nach meinen Beobachtungen möchte ich nur das niedrigste der angegebenon Maxima, $15 \mathrm{~g}$ Tabak oder etwa 3 Cigarren täglich, für ab- 
solut unschädlich halten. In einigen wenigen Fällen war die Menge des angeblichen Alcohol- und Tabaksconsums sehr gering und trotzdem bestand eine typische, unter $\mathrm{Ab}$ stinenz sehr rasch heilende Intoxicationsamblyopie. Dass in diesen Fällen das geringe Tabaksquantum, vielleicht bei vorhandener abnorm hoher Empfindlichkeit des Organismus gerade gegenüber diesem Genussmittel, beschuldigt werden muss, ist eben so wenig wahrscheinlich, als das Vorliegen anderer bisher noch wenig bekannter ätiologischer Momente, z. B. Diabetes mellitus. Vielmehr ist die Annahme nicht von der Hand zu weisen, dass es sich um Individuen handelte, welche aus irgend welchen Gründen die Wahrheit nicht eingestehen wollten, eine Vermuthung, deren Richtigkeit sich manchmal später erweisen liess (z. B. Fall 18). Einzelne Kranke gaben auch an, früher sehr stark geraucht $\mathrm{zu}$ haben, seit einigen Monaten oder Jahren aber bedeutend weniger zu rauchen. Es wäre denkbar, dass in diesen Fällen der durch den früheren starken Tabaksgenuss bereits afficirte Sehnerv auch die verminderte Tabakszufuhr nicht mehr vertragen konnte und auf sie mit einer Amblyopie reagirte. Die Filehne'sche Beobachtung, dass trotz erheblicher Herabminderung des Tabaksconsums die Amblyopie noch Fortschritte machte, spricht hierfür.

Jede der verschiedenen gebräuchlichen Arten, in welcher der Tabak dem Organismus einverleibt wird, kann zur Intoxicationsamblyopie führen, also Tabak rauchen, schnupfen und kauen. Das Einathmen der mit Tabaksstaub geschwängerten Luft erscheint wenig oder gar nicht gefährlich zu sein, sonst müssten sich unter den Tabaksarbeitern mehr derartige Amblyopen finden, während unsere Statistik nur einen einzigen Cigarrenmacher aufweist, welcher, an einer typischen Intoxicationsamblyopie erkrankt, seiner Angabe nach täglich nur zwei Cigarren rauchte, dagegen den ganzen Tag über tabakhaltige Luft einathmete. Das Tabakskauen und demgemäss auch das Zerquetschen 
der gerauchten Cigarren mit den Zähnen, scheint besonders gefährlich zu sein, ebenso auch die Benutzung unsauberer Spitzen und Pfeifen. Derartigen schwer controllirbaren Momenten ist sicher die manchmal beobachtete schädliche Wirkung geringerer Tabaksmengen zuzuschreiben. Das besonders beim Cigarettenrauchen übliche Verschlucken des Rauches wirkt vielleicht auch als besonders ungünstiges Moment mit. So gab ein 27 jähriger Friseur (Fall 1), der die ersten Spuren der Intoxicationsamblyopie (einen kleinen Defect für roth am Fixirpunkte) zeigte und gar nicht trank, an, täglich nur 6-8 Cigaretten zu rauchen, dabei aber den Rauch zu verschlucken, allerdings habe er bis vor zwei Jahren pro Tag 50-60 Cigaretten geraucht. Eine gastrische Störung war nicht nachzuweisen, so dass also, falls das Verschlucken des Rauches einen schädlichen Einfluss hat, nicht die erzeugte Verdauungsstörung, sondern die reichlichere Einverleibung der toxischen Substanz, nicht nur in dem Rauche, sondern jedenfalls auch in dem mit verschluckten Speichel, nachtheilig wirkt.

Sehschärfe. Die Sehschärfe schwankt bei der Intoxicationsamblyopie zwischen $5 / 200$, wobei - eventuell mit starken Convexgläsern $\left(+6^{\prime \prime}\right)$ - nur noch grössere Schriftproben, Snellen XVI, X oder höchstens VII 1/2 mühsam entziffert werden, bis zu ${ }^{2 \%} / 30$, wobei $\mathrm{I} / / 2$ fliessend gelesen wird. Es fällt bei den Sehprüfungen oft eine sehr mangelhafte Uebereinstimmung des Resultates bei den verschiedenen Untersuchungsmethoden auf. Bestimmt man nämlich die Sehschärfe einerseits an den in $20^{\prime}$ Entfernung hängenden gut beleuchteten Snellen'schen Tafeln, welche einzelne Buchstaben entbalten (Sehschärfe für die Ferne) und lässt andererseits die einen zusammenhängenden Text enthaltenden Snellen'schen Leseproben I1/2, III u. s. w. eventuell mit bewaffnetem Auge in geringerer Entfernung ( $3^{\prime \prime}$ bis $3^{\prime}$ ) lesen (Sehschärfe für die Nähe), so ergiebt die aus beiden Prüfungen resultirende Grösse von S nicht selten eine auf- 
fallende Differenz. So wird z. B. bei $S=20 / 50$ für die Ferne manchmal in der Nähe $I_{1}^{1} / 2$ gar nicht, sondern nur Sn II als kleinste Schriftprobe, bei. $S={ }^{20} / 70$ selbst mit Convexgläsern nicht Sn I $1 / 2$ und II, soudern nur II $1 / 2$ gelesen, bei $S={ }^{20 / 200}$ wird von einigen Kranken $S_{n} I_{1 / 2}^{1}$, von anderen nur Sn VII $1 / 2$ gelesen. Es kann vorkommen, dass derselbe Patient mit dem einen Auge, welches für die Ferne die bessere Sehschärfe hat, Sn III weniger weit liest, als mit dem in die Ferue schlechter sehenden anderen Auge, ohne dass sich eine Refractionsdifferenz beider Augen nachweisen liesse (z. B. Fall 7).

Wenn auch einzelne derartige Incongruenzen auf ungenaue Angaben der Patienten zu beziehen sind, zumal deren Intelligenz und Energie öfter durch Alcobolmissbrauch stark gelitten hat, so ist doch die mangelhafte Uebereinstimmung der Sehschärfe für die Nähe und für die Ferne bei jeder einzelnen Untersuchungsreihe in vielen Fällen so constant, dass sie für die Intoxicationsamblyopie bis $\mathrm{zu}$ einem gewissen Grade characteristisch ist. Es hat die Art und Weise des Lesens bei der Tabaksamblyopie nicht selten grosse Aehnlichkeit mit der bei Anaesthesia retinae vorkommenden. Der Tabaksamblyop betrachtet die Schrift erst eine Weile, liest dann einige Worte, worauf erst nach einer abermaligen Pause wieder einige Worte folgen. Einmal kounte bei einem Tabaksamblyopen eine deutliche Gesichtsfeldverschiebung nach dem Förster'schen Typus ${ }^{1}$ ) bei centripetaler und centrifugaler Objectführung nachgewiesen werden, es ist daher die Annahme nicht unwahxscheinlich, dass bei der Intoxicationsamblyopie öfter ein der Anaesthesia retinae ähnlicher Zustand vorhanden ist. Schön²) hat einen ähnlichen Zustand, eine leichtere Er-

1) cf. u. A.: König, Beobachtungen äber Gesichtsfeldeinengung nach dem Förster'schen Typus. Arch. f. AugenL., XXII, S. 264.

2) Die Lehre vom Gesichtsfelde. S. $120 \mathrm{f}$. 
müdbarkeit der Netzhaut bei der Intoxicationsamblyopie supponirt, aus demselben aber fälschlicher Weise die Entstehung des centralen Scotoms herleiten wollen. Möglicher Weise sind die auffallenden Differenzen der Sehschärfe bei der Tabaksamblyopie, welche sich bei Anwendung verschiedener Untersuchungsmethoden ergeben, auf einen der Anaesthesia retinae ähnlichen Zustand zurückzuführen.

Zwischen der Grösse und Beschaffenheit des Defectes und der Sehschärfe liessen sich folgende Beziehungen constatiren. Ist nur an $F$ ein Defect für roth vorhanden, so schwankt $S$ zwischen $20 / 200$, wobei noch Sn VI erkannt wird und $20 / 30$, wobei $\mathrm{Sn} \mathrm{I}^{1} / 2$ gelesen wird. Hat der Defect für roth die Gestalt eines sich von F bis M erstreckenden Ovales, so kann $\mathrm{S}$ bis auf $5 / 200$ sinken, wobei nur Sn XVI erkannt wird, und die stärkste bei der Intoxicationsamblyopie überhaupt vorkommende Herabsetzung der Sehschärfe erreicht ist, es kann aber $S$ auch noch $={ }^{20} / 30$ sein. Ist bei derselben Form des Farbenscotoms ein Theil desselben absolut defect, so ist die höchste noch beobachtete Sehschärfe $={ }^{20} / 70$. Hat der Defect für roth bereits die Grenze der Rothempfindung nach einer Richtung hin durchbrochen, so kann $S$ immer noch ${ }^{20 / 10}$ betragen, falls ein Defect für weiss nicht vorhanden ist, ja selbst bei einem so bedeutenden Defecte, dass roth nur noch nach innen von $\mathrm{F}$ erkannt wird, braucht $\mathrm{S}$ nicht unter ${ }^{20 / 70} \mathrm{zu}$ sinken. Ist jeder Defect für roth im Gesichtsfelde eben verschwunden, so beträgt $S$ mindestens ${ }^{2} \%{ }_{100}$, kann aber auch gleich $20 / 20$ sein.

Es besteht also zwischen der Grösse des Defectes für roth und weiss und der Sehschärfe nur eine sehr lockere Beziehung, indem bei derselben Beschaffenheit des Scotoms $S$ innerhalb weiter Grenzen schwanken kann. Es geht dies auch schon daraus hervor, dass manchmal trotz vollkommen unveränderten Fortbestehens des centralen Defectes sich $\mathrm{S}$ nicht unbeträchtlich hebt, während in anderen 
Fällen der Gesichtsfelddefect ohne gleichzeitige Besserung der Sehschärfe einen raschen Rückgang zeigt.

Die Zeitdauer, innerhalb welcher die Sehschärfe normale oder annähernd normale Höhe $\left(S={ }^{20} / 30\right)$ erreicht, beträgt bei den schworsten beiden in dieser Hinsicht genauer beobachteten Fällen (anfängliche Sehschärfe $5 / 200$ und ${ }^{20} / 200$ ) etwa 6 Monate, dann folgt ein Fall mit $\mathrm{S}=20 / 100$, welcher $2^{1 / 2}$ Monate bis zur Erreichung von $2 / 3$ Sehschärfe brauchte. Bei leichteren Amblyopien vergehen 3 Tage bis 1 Monat, ehe $\mathrm{S}$ auf normale Höhe gestiegen ist.

Methode der Gesichtsfeldmessung. Bevor das wichtigste pathognomonische Symptom der Intoxicationsamblyopie, der centrale Defect, eine genaue Schilderung erfährt, sollen einige zur Constatirung desselben wichtige Punkte erörtert werden. Alle folgenden Gesichtsfeldaufnahmen sind mit dem Förster'schen Perimeter gemacht worden. Als Prüfungsobjecte dienten farbige Quadrate von $5 \mathrm{~mm}$ Seitenlänge auf schwarzem Grunde. Die farbigen Papiere entstammen dem Heidelberger Farbenbuche. Untersucht wurde vorwiegend mit roth und weiss, seltener auch noch mit grün und blau. Wo durch Quadrate von der genannten Grösse kein Defect constatirt werden konnte, wurden kleinere Prüfungsobjecte von 3,2 und $1 \mathrm{~mm}$ Seitenlänge benutzt. Grössere Quadrate von 10 und $20 \mathrm{~mm}$ Seitenlänge kamen nur in seltenen Fällen und zwar ausnahmslos nur dort zur Verwendung, wo die Farbe kleinerer Objecte nicht mehr richtig erkannt wurde. Ein Quadrat von $5 \mathrm{~mm}$ Seitenlänge bedeckt genau einen Grad des Förster'schen Perimeters (Radius 1'), mit grösseren Objecten von 10 und $20 \mathrm{~mm}$ Seite, welche $2^{\circ}$ und $4^{\circ}$ bedecken und leider noch von vielen Untersuchern benutzt werden, ist ein genaues Gesichtsfeld nicht aufzunehmen. Diese grösseren Objecte können vielmehr nur als Nothbehelf in den einzelnen Fällen dienen, wo kleinere Quadrate in ihrer Farbe nicht mehr deutlich erkannt 
werden. Um einzelne anuähernd in der Richtung eines Parallelkreises rerlaufende Dimensionen des Defectes, z. B. den verticalen Durchmesser des blinden Fleckes aufzunehmen, empfiehlt es sich, das Prüfungsobject an einer innerhalb des Defectes gelegenen Stelle des Perimeterbogens festzustellen und diesen dann um seine Achse und damit zugleich um die Gesichtslinie des untersuchten Auges nach beiden Richtungen hin soweit zu drehen, bis das Object wieder erscheint. Verfährt man so in verschiedenen Parallelkreisen, so kann man die Form des Defectes sehr genau wieder geben.

Die gefundenen Resultate wurden in der letzten Zeit ausschliesslich in das neue Förster'sche Gesichtsfeldschema, bei welchem $\mathrm{F}$ mit dem Schnittpunkte der Meridiane zusammenfällt, eingezeichnet ${ }^{1}$ ). Da indessen aus früherer Zeit eine nicht unbeträchtliche Menge von Gesichtsfeldzeichnungen vorhanden waren, bei welchen entsprechend dem alten Förster'schen Schema der Mariotte'sche Fleck dem Schnittpunkt der Meridiane entspricht, so entwarf ich auf Grund sphärisch-trigonometrischer Berechnungen ein Schema, welches die Uebertragung der in das eine Schema eingezeichneten Gesichtsfelder in das andere ermöglicht. Da bei der früheren Methode, $\mathrm{M}$ in den Mittelpunkt des Gesichtsfeldschemas zu verlegen, eine Vergrösserung des blinden Fleckes sich viel besser constatiren lässt als bei der jetzt üblichen Methode, den Fixirpunkt mit dem Kreuzungspunkte der Meridiane zusammen fallen zu lassen, die jetzige Methode aber für die Aufnahme eines Defectes an F die einzig rationelle ist, so wurden in einigen Fällen beide Methoden vereinigt. Es wurde nämlich der Defect an $\mathrm{F}$ bei Fixation des mit dem Drehpunkte des Perimeters zusammenfallenden elfenbeinernen Knopfes, die Ausdehnung von M aber bei Fixation eines im horizontalen Meridiane

1) Die Figuren 1-30 zeigen nicht das ganze Gesichtsfeldschema, sondern nur den mittleren Theil desselben bis zum 40. Parallelkreise. 
$15^{\circ}$ nach innen gelegenen Punktes aufgenommen; die für das Scotom an F gefundenen Maasse wurden direct, die für $\mathrm{M}$ gefundenen nach vorheriger Umrechnung mit Hülfe des erwähnten Uebertragungsschemas in das neue Förster'sche Gesichtsfeldschema eingezeichnet. Da das letztere in der gebräuchlichen Form zu klein ist, um die gefundenen Gesichtsfeld- und Defectgrenzen bis auf $1^{0}$ genau einzutragen, so wurden Schemata von der doppelten Grösse benutzt ${ }^{1}$ ), welche für alle genaueren Sehfeldaufnahmen ser zu empfehlen sind.

Die beigegebenen Gesichtsfeldzeichnungen sind derartig aufgenommen, dass in 5 Meridianen, also 10 Radien des Gesichtsfeldes jeder als Grenze des Sehfeldes oder Defectes gefundene Parallelkreis durch einen Punkt bezeichnet wurde. Diese Punkte sind untereinander durch gerade Linien verbunden worden, wie dies in dem Förster'schen Gesichtsfeldschema für die Aussengrenzen ebenfalls geschehen ist. Es scheint mir dies wahrheitsgetreuer zu sein, als die Verbindung der einzelnen Punkte durch gebogene Linien, deren Krümmung mehr der Phantasie des Untersuchers als dem objectiven Befunde entspricht, ja letzteren bis zu einem gewissen Grade verschleiert. Wo es nothwendig erschien und die Zeit es gestattete, wurden mehr als 5 Meridiane, manchmal in Intervallen von $20^{\circ}$ zu $20^{\circ}$ oder selbst $10^{\circ}$ zu $10^{\circ}$ geprüft.

Gesichtsfeld, Für das Gesichtsfeld bei der Intoxicationsamblyopie ergiebt sich folgender characteristischer Befund. Es ist in allen Fällen ein centraler Defect für kleine rothe Objecte bei normalen Aussengrenzen des Sehfeldes vorhanden. Nur einmal zeigte sich eine geringe Einengung des Gesichtsfeldes für weiss mit dem für Anaesthesia retinae characteristischen Förster'schen Verschiebungstypus. Der centrale Defect ist ein negatives Scotom. Inner-

1) Dieselben sind zu beziehen von Theiner \& Meinicke in Breslau, Ring 1. 
halb des Defectes erscheint ein rothes Object sowohl auf weissem wie auf schwarzem Grunde entweder vollkommen schwarz, oder seine Farbe ändert sich, sie wird in einem anderen Tone gesehen und als "matter", manchmal als "gelb" bezeichnet. Weiss erscheint an der defecten Stelle in der Regel weniger hell, "graulich", in einzelnen Fällen verschwindet das weisse Object stellenweise aber auch vollständig, so dass der Defect in diesen Partien absolut ist. Die mangelhafte Farbenempfindung innerhalb des Scotoms giebt sich subjectiv oft in eigenthümlicher Weise zu erkennen. So konnte ein Patient die rothen Kirschen auf den Bäumen nicht mehr von dem grünen Laube unterscheiden, ein Schmied vermochte das rothglühende Eisen im Feuer nicht zu erkennen, und ein Jäger bemerkte den grauen Rücken eines im grünen Rasen sitzenden Hasen nicht eher, als das Thier aufsprang und sich durch seine Bewegung verrieth.

Der centrale Defect ist nicht so scharf begrenzt, als es nach den Gesichtsfeldzeichnungen den Anschein haben könnte, vielmehr geht er allmälig durch eine Zone verminderter Empfindung in die intacte Gesichtsfeldpartie über, man ist daher genöthigt, sobald roth innerhalb des Scotoms nicht "schwarz" erscheint, nur diejenige Partie als Defect anzusehen, innerhalb welcher das rothe Quadrat in einer für den Kranken auffallenden Weise seine Farbe, Helligkeit oder Nüance ändert. Die Grösse des Defectes ist daher oft von dem subjectiven Ermessen des Untersuchers abbängig. In derartigen Fällen wird bei der Anwendung lsleinerer Objecte $\left(3 \mathrm{~mm}^{2}\right.$ und darunter) das Resultat oft exacter, als bei der Benutzung grösserer $\left(5 \mathrm{~mm}^{2}\right)$. Ein ausgebildeter centraler Defect verräth sich meist schon dadurch, dass beim monoculären Fixiren cines der mittleren Buchstaben in einem längeren Worte die nach aussen von dem fixirten Punkte gelegenen Theile des Wortes undeutlicher erscheinen als die nach innen gelegenen. 
Entwickelung des centralen Defectes. Die Entstehung, Vergrösserung und Rückbildung des centralen Defectes bei der Intoxicationsamblyopie erfolgt in einer durchaus gesetzmässigen Art und Weise, welche für dieses Krankheitsbild characteristisch ist. Das centrale Scotom der axialen retrobulbären Neuritis zeigt nach Wilbrand einen ähnlichen Verlauf, unterscheidet sich aber, abgesehen von anderen noch zu erwähnenden Merkmalen, besonders dadurch, dass es stets absolut ist, von dem Defecte der Intoxicationsamblyopie. Das Fortschreiten des Defectes wird man nur in Ausnahmefällen an demselben Kranken beobachten können, da die Patienten entweder Abstinenz üben und geheilt oder doch gebessert werden, oder aber die ertheilten Rathschläge nicht befolgen und daher den Arzt nicht wieder aufsuchen. Wir können uns also über die Entwickelung des centralen Defectes nur durch Combination vieler einzelner Fälle, welche verschiedene Stadien darstellen, unterrichten. Wegen des nicht scharf markirten Beginnes der Erkrankung ist über die zur Entstehung der verschiedenen Scotomtypen erforderliche Zeit nichts genaneres bekannt.

Bei den allerersten Anfängen der Intoxicationsamblyopie findet sich ein kleiner Defect für roth an $\mathrm{F}$ in der Richtung auf $\mathrm{M}$ zu sich erstreckend. Das Scotom überschreitet $\mathbf{F}$ nach innen hin nicht, oder nur unbedeutend und hat eine Ausdehnung ron $5^{\circ}$ und weniger. Dieser Defect ist meist nur mit ganz kleinen rothen Quadraten von 2 und $1 \mathrm{~mm}$ Seitenlänge nachweisbar; er ist stets auf beiden Augen vorhanden, nur in ganz frischen Fällen scheint er auch einseitig vorzukommen, wie das Uhthoff auch einmal beobachtet hat.

Der einzige derartige Fall betraf einen 27 jährigen Friseur (Fall 1), welcher mit dem rechten Auge bei einer Sebschärfe von $2 \% / 200$ mit $\left(+10^{\prime \prime}\right)$ Sn III noch las und den genannten Defect für roth und grün, aber nicht für weiss an $F$ 
in einer Ausdehnung von $2^{\circ}$ zeigte, während sich links bei $\mathrm{S}={ }^{20} / 30$ auch mit $1 \mathrm{~mm}$ grossen rothen Quadraten kein deutlicher Defect nachweisen liess, nur erschien ein derartiges Object an $F$ etwas dunkler als unmittelbar daneben. Patient war schon vor vier Monaten wegen asthenopischer Beschwerden in Folge von Hypermetropie in der Poliklinik gewesen, $\mathrm{S}$ betrug damals auch auf dem rechten Auge 2\% rapie bestand in Abstinenz und in der Darreichung von Jodkalium, woron im Ganzen $20 \mathrm{~g}$ gebraucht wurden. Schon nach neun Tagen hob sich die Sehschärfe des erkrankten Auges auf $20 / 40$, nach 21 Tagen auf $2 \% / 30$ und der centrale Defect war vollkommen verschwunden. Patient hatte, wie schon oben (Seite 25 f.) erwähnt, früher sehr stark, in der letzten Zeit immer noch stark Cigaretten geraucht und dabei den Rauch derselben verschluckt.

Ein derartiges kleines Scotom an $\mathrm{F}$ wird nur selten beobachtet, da einerseits die Kranken in diesem Stadium wegen der nur geringen Sehstörungen den Arzt noch nicht aufzusuchen pflegen, andererseits aber der Defect wegen seiner Kleinheit sehr leicht übersehen wird.

Als Typus diene Figur 7, dieselbe zeigt den Defect für ein rothes Object von $5 \mathrm{~mm}$ Seitenlänge auf dem rechten Auge des 32 jährigen Arbeiters Gustav B. (Fall 2.) Roth verschwindet an der defecten Stelle nicht vollkommen, sondern erscheint nur matter; für weiss ist kein Defect vorhanden, die Ausdehnung ron $\mathrm{M}$ ist nicht genauer bestimmt worden. Das linke Auge zeigt den typischen ovalären Defect für roth. $S=20 / 40$ für jedes Auge. Patient ist leidenschaftlicher Raucher und starker Trinker. Die Sehstörung soll erst seit wenigen Tagen bestehen, der Fall scheint also ganz frisch gewesen zu sein. Ueber den weiteren Verlauf ist nichts bekannt.

Manchmal erstreckt sich das Scotom von $F$ aus nicht gerade nach aussen hin, sondern nach aussen oben oder aussen unten, immer aber überragt es $F$ nach innen hin wenig oder gar nicht. Gleichzeitig ist der blinde Fleck für roth meist etwas vergrössert auf $8^{\circ}-10^{\circ}$, und intelligente Kranke geben an, dass sie auch in der noch roth empfindenden Partie zwischen F und M das rothe Object v. Graefe's Archì für Ophthalmologie. XXXVII. 1. 
nicht so deutlich wahrnehmen, als nach innen von $\mathrm{F}$ oder aussen von $M$. In seltenen Fällen scheint, noch ehe ein Defect an $\mathrm{F}$ nachweisbar ist, eine Vergrösserung von $\mathbf{M}$ auf $\mathrm{F} \mathrm{zu}$ vorhanden $\mathrm{zu}$ sein.

Dieses Vorkommniss zeigt das Gesichtsfeld des 50 jährigen Schmierers an der Eisenbahn, Friedrich T. (Fall 3). Auf dem rechten Auge ist ein typischer eiförmiger Defect für roth vorhanden, während sich links (Fig. 15) nur der blinde Fleck vergrössert zeigt, aber keiv Defect an $\mathbf{F}$ nachzuweisen ist, Aussengrenzen für roth normal. Auffallend ist die schlechte Sehschärfe; es werden mit $\left(+6^{\prime \prime}\right)$ mit jedem Auge nur Buchstaben yon Sn X erkannt. Missbrauch ron Tabak und Alcohol wird zugegeben. Leider kronnte nur eine Perimeteruntersuchung vorgenommen werden, da der Kranke nach wenigen Tagen aus der Behandlung entschwand. Eine briefliche Anfrage ergab, dass die zu Hause geübte Abstinenz von gutem Erfolge begleitet war, und der Kranke jetzt wieder seinen Dienst vollkommen ausüben kann.

Bei der Rückbildung des Defectes hat man öfter Gelegenheit, noch eine Vergrösserung von $\mathrm{M}$ zu constatiren, während an $F$ kein oder nur ein unbedeutender Defect vorhanden ist (Fig 26).

Schreitet die Krankheit weiter fort, so vergrössern sich die beiden Defecte an $\mathrm{F}$ und $\mathrm{M}$, wachsen auf einander $\mathrm{zu}$ und lassen nur noch eine schmale Brücke zwischen sich frei, bis sie sich schliesslich vereinigen. Diese Vereinigung geschieht meist nicht in der Verbindungslinie ron $F$ und $M$, sondern oberhalb oder unterhalb derselben, sodass in den hufeisenförmigen Defect von oben oder unten her eine roth empfindende Halbinsel hineinragt. Manchmal erfolgt die Vereinigung gleichzeitig durch zwei Fortsätze oberhalb und unterhalb des horizontalen Meridianes, wodurch eine kleine roth empfindende Insel inmitten des ringförmigen Defectes entsteht.

Einen Defect an F, der M noch nicht erreicht hat, zeigt das Gesichtsfeld des 46 jährigen Arbeiters August R. (Fall 4). Patient bemerkt seit sechs Wochen eine allmälige Abnabme 
der Sehschärfe auf beiden Augen. Gegenwärtig ist $S={ }^{20} / 200$ und mit $\left(+6^{\prime \prime}\right)$ wird Sn II in 4" erkannt. Das rechte Auge zeigt den typischen ovalen Defect für roth, das linke Auge (Fig. 1) einen Defect an. $F$, der von dem blinden Fleck noch durch eine rothempfindende Brücke getrennt wird.

Ein etwas fortgeschritteneres Stadium zeigt Figur 2, das Gesichtsfeld des linken Auges des 38 jährigen Kutschers August W. (Fall 5). Die Sehschärfe des linken Auges betrug anfangs $2 \%$, nach zehn Tagen wurde mit $\left(+10^{\prime \prime}\right)$ Sn I ${ }^{1 / 2}$ bis $7^{\prime \prime}$ gelesen und nach 27 Tagen war $\mathrm{S}$ auf $20 / 40$ gestiegen. Fig. 2 zeigt den Defect für roth $5 \mathrm{~mm}^{2}$, ein Defect für weiss ist nicht vorhanden. Ueber das Gesichtsfeld des rechten Auges (Figg. 3 und 4) soll weiter unten berichtet werden.

Eine noch weitere Entwickelung hat der Defect bei dem 25 jährigen Droschkenkutscher Gottlieb K. crreicht (Fall 6). K. raucht täglich $10-12$ schlechte Cigarren, trinkt reichlich Schnaps und Bier, sehläft sehr wenig, oft nur 4 Stunden, manche Nacht auch gar nicht, hat aber angeblich guten Appetit. Eine Abnahme der Sehschärfe bemerizte er zuerst vor 4 Monaten, als er zu einer militärischen Schiessübung eingezogen war. Seitdem ist eine weitere Verschlechterung eingetreten, gegenwärtig beträgt für jedes Auge $S=20 / 200$, wobei noch Sn II erkannt wird. Das rechte Auge (Fig. 5) zeigt einen hufeisenförmigen Defect für roth, in welchen von unten her eine noch functionirende Halbinsel hineinragt, während links (Fig. 6) der Defect bereits die typische Eiform angenommen hat; nur ist in seiner Mitte zwischen $F$ und M noch eine kleine roth empfindende Insel ausgespart.

Bei den meisten zur Beobachtung kommenden Fällen ist auch diese roth empfindende Insel oder Halbinsel bereits mit in den Defect einbezogen worden, wodurch derselbe seine typische Form erhält. Er ist dann eiförmig mit horizontal gestellter langer Achse, das breite Ende des Seotoms liegt bei F, das schmälere bei M. Der Defect erstreckt sich zwischen $\mathrm{F}$ und $\mathrm{M}$ und überragt beide meist nur sehr wenig; er wird durch den horizontalen Meridian in der Regel in zwei gleich grosse Hälften, eine obere und eine untere getheilt. Die aus 33 Fällen berechnete Ausdehnung dieses Defectes ergiebt folgende Zahlen: Die in- 
nere Grenze liegt unmittelbar an $\mathrm{F}$ bis höchstens $10^{\circ}$, durchschnittlich $4^{0}$ nach innen davon, die äussere Grenze schwankt zwischen $16-22^{\circ}$ und beträgt durchschnittlich $18^{\circ}$. Die Gesammtausdehnung des Scotoms in horizontaler Richtung schwankt zwischen $18^{\circ}-29^{\circ}$ und erreicht im Durchschnitt $22^{\circ}$. Begrenzt man die in vertikaler Richtung breiteste Stelle des Scotoms durch zwei Linien, welche dem horizontalen Meridian parallel verlaufen, so schneiden diese den verticalen Meridian oben zwischen dem $3 .^{\circ}$ und $14 .^{\circ}$, unten zwischen dem $4 .^{\circ}$ und $12 .^{\circ}$ nach jeder der beiden Richtungen hin durchschnittlich im 8. Grade $^{1}$ ). Der grösste Gesammtdurchmesser in vertikaler Richtung schwankt zwischen $8^{\circ}$ und $24^{\circ}$ und beträgt durchschnittlich $16^{\circ}$. Es ist hierbei noch zu bemerken, dass diejenigen Defecte, welche sich nach oben oder unten weiter als $8^{\circ}-10^{\circ}$ erstrecken, nicht etwa in toto verbreitert sind und dadurch statt eiförmig mehr kreisrund werden, sondern sie senden nur eine Spitze oder einen Zipfel über den 8 . bis 10. Grad hinüber. Wenn auch die Gestalt des ausgebildeten typischen Defectes eiförmig ist, so beobachtet man doch nicht selten einerseits Defectformen, welche diese Gestalt noch nicht erreicht haben, sondern, besonders zwischen $\mathrm{F}$ und $\mathrm{M}$, noch Einschnürungen zeigen, andererseits aber auch ausgebildete Defecte, welche in Folge weiterer Entwickelung zipfel- oder zungenförmige Vorsprünge, meist nach oben oder unten hin, entsenden.

Als Beispiele für diesen typischen Defect können die Figuren 4, 8, 12, 20, 27-29, 31-33 und 36 dienen.

Figur 8 zeigt das Gesichtsfeld des 47 jährigen Schiffers Rudolf G. (Fall 7). Derselbe sucht am 23. Mai 1877 die Poli-

1) Diese Messung gilt nux für das auf eine ebene Fläche projicirte Scotom. Mathematisch richtiger wäre es, dasselbe auf eine Kugelfläche, wie sie z. B. das Scherk'sche Perimeter bildet, zu zeichnen, und dann die Messung vorzunehmen. Der durch unsere Methode begangene Fehler ist indessen unwesentlich. 
klinik mit der Klage anf, dass er eine Abnahme seines Sehvermögens bemerke. Patient raucht täglich $25 \mathrm{~g}$ Hamburger Shag, eine seiner Angabe nach besonders starke Tabakssorte, aus der Pfeife, daneben auch einige Cigarren und kaut noch dazu den ganzen Tag über Tabak. Alcoholische Getränke nimmt er, solange er sich auf dem Schiffe befindet, gar nicht zu sich, was auch vollkommen glaubwürdig erscheint, da der Kranke durchaus keinen Säuferhabitus darbietet und keinen Tremor hat. Seit dem Frühjahr schläft der Kranke schlecht, manche Nacht nicht zwei Stunden, sein Appetit ist sehr verringert, er isst zum ersten Frühstück nichts, sondern macht nur eine Mittags- und eine Abendmahlzeit, in der zwischen beiden liegenden Zeit verspürt er keinen Hunger. Die Untersuchung der Augen ergiebt objectiv nichts abnormes, dagegen ist die Sehschärfe des rechten Auges auf $2 \%$, des linken Auges auf $20 / 70$. herabgesetzt, und es wird mit $\left(+10^{\prime \prime}\right)$ rechts Sn II von $3-7^{\prime \prime}$, links Sn $I^{1 / 2}$ von $3-7^{\prime \prime}$ gelesen. Es zeigt sich also hier die schon erwähnte Incongruenz der Sehschärfe für die Nähe und für die Ferne, indem das für die Ferne bessere Auge nur Sn II, das schlechtere aber Sn $\mathrm{I}^{1} / 2$ liest. Das Gesichtsfeld beider Augen zeigt bei normalen Aussengrenzen für roth einen centralen Defect für diese Farbe zwischen $F$ and M, der durch eine Einschnürung in der Mitte eine Beutelform erhält. (Die doppelt schraffirte Partie in Fig. 8 zeigt das Scotom des linken Anges.) Es hatten sich hier die beiden Defecte bei $\mathbf{F}$ und $\mathbf{M}$ ausnahmsweise durch einen in der Horizontalen gelegenen Fortsatz vereinigt. Bei diesem Falle bot sich nun die ausserordentlich seltene Gelegenheit, das weitere Wachsen des Defectes zu beobachten. Da nämlich der Kranke das Rauchen nicht einstellte, so hatte, als er sich vier Monate später, am 27. September desselben Jahres, vorstellte, der Defect an Grösse zugenommen. Die Sehschärfe betrug nur ${ }^{20} / 200$ und mit $\left(+10^{\prime \prime}\right)$ wurde Sn III erkannt. P. hat seinem eigenen Geständnisse nach weiter geraucht und gepriemt und will erst seit drei Wochen Abstinenz geübt haben, seitdem soll sich die Sehschärfe bereits etwas gehoben haben. Seit derselben Zeit hat sich Schlaf und Appetit wesentlich gebessert, P. isst doppelt so viel wie früher. Leider stellte sich der Kranke nicht mehr vor. Die einfach schraffirte Partie in Fig. 8 zeigt die Ausdehnung des Defectes für roth am 27. September.

Der eiförmige Defect für roth vergrössert sich beim 
weiteren Wachsen nicht nach allen Seiten hin gleichmässig, sondern zunächst nur nach oben hin, bis er die Grenze der Rothempfindung erreicht, der Defect „ist nach oben durchgebrochen". Das Gesichtsfeld für roth bildet daun einen Halbmond oder einen Theil eines Kreisringes, dessen offene concare Seite sich nach oben hin wendet. Die Durchbruchstelle kann oberhalb von $\mathrm{F}$ oder von $\mathrm{M}$ liegen oder so ausgedehnt sein, dass sie das obere $1 / 3$ des noch rorhandenen ringförmigen Gesichtsfeldes für roth einnimmt. Seltener erfolgt der Durchbruch nicht direct nach oben, sondern nach oben aussen hin, jedoch stets oberhalb des horizontalen Meridianes. Manchmal sind zwei Durchbruchstellen vorhanden, welche noch eine kleine rothempfindende ungefähr über der Mitte zwischen $F$ und M gelegene Insel einschliessen. In keinem Falle wurde zuerst ein Durchbruch nach unten constatirt. Die Vergrösserung des centralen Defectes erfolgt nicht immer nur in der Weise, dass das Scotom sich nach oben hin ausdebnt, sondern es wächst demselben auch manchmal eine Einziehung der äusseren Grenze des Gesichtsfeldes für roth entgegen, so dass die schmale zwischen beiden befindliche roth empfindende Brücke schliesslich durchbrochen wird. Einige Gesichtsfelder zeigen sämlich an der voraussichtlichen Durchbruchsstelle eine deutliche Einziehung der im übrigen normalen Aussengrenzen des Gesichtfeldes für roth, (ähnlich wie in Fig. 12, welche einen in der Rückbildung befindlichen Fall zeigt).

Bei der perimetrischen Untersuchung mit sehr kleinen Objecten kann man leicht zu einer irrthümlichen Deutung des erhaltenen Gesichtsfeldes veranlasst werden. Es zeigt nämlich eins der hierher gebörigen Gesichtsfelder einen auf dem linken Auge oberhalb, auf dem rechten Auge oberhalb und unterhalb von $M$ bereits durchgebrochenen Defect für roth, dieser Defect hat aber den Fixationspunkt noch nicht erreicht, endet vielmehr innen zwischen $F$ und M. Dieses merkwürdige Gesichtsfeld ist mit einem rothen 
Quadrate von uur $1 \mathrm{~mm}$ Seitenlänge aufgenommen worden, wesshalb die Aussengrenzen naturgemäss sehr eng sind, so dass eine geringe Vergrösserung des Mariotte'schen Fleckes nach oben oder unten hin, wie sie zuweilen im Anfangsstadium der Intoxicationsamblyopie und auch bei der Riïckbildung des Defectes beobachtet wird (z. B. Fig. 26), hinreicht, den Defect als bereits durchgebrochen erscheinen zu lassen. Es ist also dieses Gesichtsfeld als ein solches anzusehen, bei welchem nur der blinde Fleck etwas vergrössert, ein Defect an F aber noch nicht vorhanden ist, dies beweist auch schon die gute Sebschärfe $\left({ }^{20} / 20\right.$ auf dem besseren Auge). Es empfiehlt sich daher, die Aussengrenzen des Gesichtsfeldes für roth stets mit einem Objecte von $5 \mathrm{~mm}$ Seitenlänge aufzunehmen, da die gefundenen Gesetze nur für ein mit einem derartigen Objecte aufgenommenes Farbenfeld gelten, für die Untersuchung der centralen Defecte selbst kann man danu die oft nicht zu entbehrenden kleineren Objecte verwenden (z. B. Fig. 23-26).

Die beschriebene Form eines nach oben durchgebrochenen Defectes zeigt das Gesichtsfeld des 68 jährigen Schuhmachers Franz H. (Fall 8), welcher am 19. Febrtar 1884 wegen einer seit einem halben Jahre bestehenden progressiren Abnahme der Sehschärfe die Klinik aufsuchte. P. ist starker Raucher. Pap. opt. sehr blass, Pupillen eng und starr. Mit $\left(+10^{\prime \prime}\right)$ werden rechts nur Buchstaben von Sn V, links von Sn VII $1 / 2$ erkannt. Das Gesichtsfeld des rechten Auges (Fig. 9) zeigt bei normalen Aussengrenzen für roth einen grossen nach oben hin durchgebrochenen Defect für roth, aber nicht für weiss. Das linke Auge zeigt ebenfalls einen centralen Defect, dessen Ausdehnung nicht genauer untersucht worden ist. Dem P. wurde strenge Abstinenz auferlegt und Laxantien gereicht. Nach 14 Tagen hatte sich $S$ etwas gehoben, indem jetzt mit jedem Auge $\mathrm{Sn} V$ gelesen wurde, die Durchbruchstelle des Defectes auf dem rechten Auge hatte sich geschlossen, und es bestand an dieser Stelle nur noch eine leichte Unsicherheit der Rothempfindung, das Gesichtsfeld für roth bildete demnach einen Ring mit dem bekannten ovalen Defecte im Centrum. P. hat sich nicht wieder rorgestellt. 
Ein mehr nach aussen als nach oben bin durchgebrochener Defect ist in Fig. 10 dargestellt; dieselbe zeigt das Gesichtsfeld des linken Auges des 46 jährigen Maurers Carl Sch. (Fall 9.) Derselbe giebt an, seit zwei Monaten schlechter zu sehen, und zwar im Schatten noch etwas besser als bei Sonnenschein. P. raucht täglich über $60 \mathrm{~g}$ Rippentabak und trinkt etwa 1 Liter Schnaps; Schlaf und Appetit angeblich gut. Die Sehsehärfe ist auf jedem Auge auf das Zählen ron Fingern in $7^{\prime}$ herabgesetzt, mit $\left(+10^{\prime \prime}\right)$ werden Buchstaben von Sn V erkannt. Der Augenspiegel zeigt sehr blasse Pap. opt. Fig. 10 giebt das Gesichtsfeld des linken Auges für roth $5 \mathrm{~mm}^{2}$ wieder. Auf dem rechten Auge ist ebenfalls ein nicht genauer untersuchter centraler Defect für roth vorhanden.

Einen an zwei Stellen durchgebrochenen Defect zeigt Fig. 11 von dem linken Auge des 34 jährigen Bahnarbeiters Hermann R. (Fall 10) herstammend. Derselbe suchte am 6. November 1876 die Poliklinik wegen hochgradiger, seit $1 / 4 \mathrm{Jahr}^{\mathrm{r}}$ bestehender Amblyopie auf. R. raucht täglich ausser $50 \mathrm{~g}$ Rippentabak noch Cigarren und trinkt einen Liter Schnaps pro Tag. Schlaf gut, Appetit schlecht, Strhlgang regelmässig täglich einmal. Die Sehschärfe ist auf das Zählen von Fingern in 15' herabgesetzt. Das Gesichtsfeld zeigt bei normalen Aussengrenzen für weiss and roth einen centralen Defect für roth und grün, aber nicht für blau und weiss, selbst nicht bei Anwendung kleiner Prüfungsobjecte. Der eiförmige centrale Defect hat auf dem rechten Auge die Grenze der rothempfindenden Gesiehtsfeldpartie nach oben hin an einer Stelle durchbrochen, während linirs (Fig. 11) dieser Durchbruch an zwei nebeneinander liegenden Stellen, welche eine kleine roth empfindende Insel umschliessen, erfolgt ist. Unter Abstinenz hob sich innerhalb 19 Tagen die Sehschärfe des linken Auges auf $20 / 40$, es schloss sich zumächst die innere und dann die äussere Durchbruchsstelle, so dass das Gesichtsfeld für roth einen Kreisring bildete, dessen obere Partie allerdings noch sebr schmal war (Fig. 12), Auf dem rechten Auge hob sich in der gleichen Zeit $\mathrm{S}$ auf ${ }^{20} / 30$, und die Durchbruchsstelle des Defectes verkleinerte sich zwar, versehwand aber nicht vollkomlzommen. Acht Jahre später, am 30. Mai 1884 suchte der Kranke wegen beginnender Presbyopie wiederum die Poliklinik auf, die Sehschärfe betrug auf jedem Ange ${ }^{20} / 30$ und Sn III wurde bis $24^{\prime \prime}$ gelesen. Der Augenspiegel zeigte auch jetzt: noch eine auffallende Blässe der Sehnervenpapillen, doch liess. 
sich im Gesichtsfelde auch mit $2 \mathrm{~mm}^{2}$ grossen rothen Objecten kein Defect mehr nachweisen, so dass $R$. als vollständig gcheilt angesehen werden muss.

Hat der Defect die Grenze der Rothempfindung nach oben hin durchbrochen, so durchbricht er sie bei weiterem Fortschreiten auch nach unten zu. Die Durchbruchsstellen sind Anfangs schmal, verbreitern sich aber später, so dass das Gesichtsfeld für roth dann aus zwei vollkommen von einander getrennten Hälften, einer äusseren und einer inneren besteht.

$\mathrm{Zu}$ dieser Kategorie gehört das Gesichtsfeld des 60 jälrigen Obersteuercontrolleurs Hermann $N$. (Fall 11), dessen ausführliche, in mehrfacher Hinsicht interessante Krankengcschichte ich Herrn Dr. Baer verdanke. Herr N. stellte sich am 19. Juni 1872 zum ersten Male vor mit der Angabe, dass er seit zwei Jahren eine allmälige Verschlechterung des Sehens bemerke, er habe namentlich bei hellem Lichte einen Nebel vor den Augen, während er im HalbdunkeIn etwas besser sähe. Die Sehschärfe betrug damals $20 / 50$, mit $+10^{\prime \prime}$ wurde Sn I $1 / 2$ von $7-10^{\prime \prime}$ gelesen. Der Augenspiegel ergab eine mässige Abblassung der Pap. opt. bei normalem Gefässcaliber. Das Gesichtsfeld zeigte einen centralen Defect für roth zwischen $F$ and M. Die Diagnose wurde auf Tabaksamblyopie gestellt und dem Kranken Abstinenz empfohlen.

Anamnestisch liess sich noch Folgendes eruiren. N. hat früher stets gut gesehen, er raucht seit seinem 17. Lebensjahre anfänglich $5-6$, seit 18 Jahren aber wohl 12 meist starke Cigarren pro Tag und schnupft seit derselben Zeit stark. Im Jahre 1870 beim Ausbruche des Krieges erlitt der Kranke bedeutende pecuniäre Verluste und der Kummer und Schmerz darüber liess ihn oft nicht einschlafen. Um Grübeleien $z u$ entgehen las er oft bis Nachts $1-2$ Uhr im Bette und rauchte dazn sehr kräftige Cigarren. Getrunken hat N. täglich zwei bis drei Kuffen Bayerisch Bier und zum Frühstück ein Schnapsglas alten Korn, mitunter auch 1-2 Flaschen Wein in der Woche. Auf seinen Dienstreisen trank or 5-6 Glas Bier pro Tag.

In diesem Falle war sicher allein der Tabak, und nicht der in nur mässiger Menge genossene Alcohol die Ursache der Amblyopie. Ferner verdient noch der Umstand besonders her- 
vorgehoben zu werden, dass $N$., solange er sich eines allgemeinen Wohlbefindens erfreute, das starke Rauchen gut vertrug, erst als ihm Kummer und Sorge die Nachtruhe raubten, und sein Organismus durch den Schlafmangel geschwächt war, machten sich die Folgen des übermüssigen Tabalssgenusses geltend.

Der Kranke hat die ihm damals empfohlene Abstinenz nur kurze Zeit durchgeführt, das Sehvermögen verfiel daher nach einer vorübergehenden Besserung immer mehr und mehr, so dass er Ende 1874 selbst mit seiner Brille $\left(+14^{\prime \prime}\right)$ nicht mehr gedruckte Schrift lesen konnte.

An 20. April 1875 stellte sich Herr N. wieder vor. Die Sehschärfe war $20 / 200$, mit $\left(+8^{\prime \prime}\right)$ wurde nur Sn XII erkannt. Die Pap. opt. waren sehr blass. Das Gesichtsfeld des rechten Auges (Fig. 16) zeigte nach innen von $F$ noch eine schmale halbmondförmige, aussen nur noch eine ganz kleine roth empindende Partie, welche durch eineu breiten Defect von einander getrennt waren. Das linke Auge zeigte einen sehr ausgedehnten centralen ovalären Defect für roth, welcher nach oben an zwei Stellen durchgebrochen war (Fig. 18). Den Kranken wurde auf's Neue strenge Enthaltsamkeit eingeschärft Er unterliess jetzt das Rauchen und Trinken fast ganz, in Folge dessen wurde dor Appetit reger, der Schlaf besser und die Sehschärfe begann sich zi heben.

Am 3. August 1875 betrag $S=20 / 50$ and mit $\left(+8^{\prime \prime}\right)$ wurde $\mathrm{Sn} \mathrm{I} / 2$ gelesen. Dio Gesichtsfelder für roth zeigten folgende Teränderung. Der Defect des linken Auges (Fig. 19) hatte sich soweit verkleinert, dass er nur noch ein etwas ausgedehntes, auf allen Seiten ron einer roth empfindenden Zone umgebenes Scotom darstellte, während rechts (Fig. 17) der Defect oben noch eine breite Durchbruchsstelle zeigte. Der Kranke lebte weiter enthaltsam und gebrauchte nebenbei Abführpillon aus Aloë und Cologuinthen, sowie feuchte Einwickelungen des Körpers.

Am 27. November 1875 war der Defect für roth vollkommen verschwanden und $S$ betrug ${ }^{20} / 20$. Trotzdem der Kranke von da an wieder täglich $4-5$ Pfeifen Tabak und einige Cigarren rauchte, auch 2-3 Seidel Bier trank nnd selbst das Schnupfen wieder aufnahm, blieb er doch gesund, wie $1 / 4$ Jahr später constatirt wurde.

Sobald der centrale Defect durch seine Ausdehnung nach oben und unten hin das Gesichtsfeld für roth in 
zwei seitliche Hälften getrennt hat, vergrössert er sich zuuächst nur auf Kosten der äusseren Gesichtsfeldhälfte. Die Rothempfindung kann in derselben rollkommen verschwinden, während die innere Hälfte oft noch ihre volle Integrität bewahrt und namentlich ihre peripheren nach innen bin gerichteten Grenzen für roth keine Einschränkung zeigen. Die äussere Grenze dieses Gesichtsfeldrestes für die Rothempfindung fällt meist mit dem durch $\mathrm{F}$ gezogenen verticalen Meridiane zusammen oder weicht von demselben etwas nach innen hin zurück, überragt ihn aber auch manchmal oben oder unten mit einem Zipfel. Die letzten Reste der Rothempfindung erhalten sich ausnahmslos nach innen von F im Bereiche des Fasciculus non cruciatus. Die mir vorliegenden sieben Fälle, bei welchen diese Gesichtsfeldform vertreten ist, zeigen für den roth empfindenden Rest des Sehfeldes meist die Form eines Halbkreises (Fig. 13), dessen Durchmesser vertical gestellt ist und durch $\mathrm{F}$ oder etwas nach innen davon verläuft, während die convexe Seite gegen die innere Gesichtsfoldperipherie hingekehrt ist. Ein derartiges Gesichtsfeld kann eine gewisse Aehnlichkeit mit temporaler Hemianopsie haben, unterscheidet sich ron derselben jedoch durch die für weiss und blau vollkommen normalen Aussengrenzen. Neben dieser Gesichtsfeldform kommt noch eine andere vor, bei welcher die Empfindung für roth nach innen von $\mathrm{F}$ noch in einer ungefähr mondsichelförmigen Partie erhalten ist (Fig. 14). Der Krümmungsmittelpunkt der beiden gebogenen Begrenzungsflächen dieses Halbmondes oder richtiger Kreisringsectors fällt ungefähr mit $F$ zusammen, so dass die nach $\mathrm{F}$ hin gekehrte Concavität der Sichel zehn und mehr Grade von $F$ entfernt bleibt, während die convexe Seite in der Gegend des 30. Parallelkreises verläuft (Figg. 14, 34 und 35). Nicht selten überragt auch hierbei das eine Ende der. Sichel den verticalen Meridian etwas nach aussen. $\mathrm{Ob}$ diese zweite Form bei der reinen uncomplicirten 
Tabaksamblyopie vorkommt, vermag ich bei der noch zu geringen Zahl einschlägiger Fälle nicht mit voller Sicherheit anzugeben. Diese Gesichtsfeldveränderung ist mehr für Neuritis axialis charakteristisch. Der eine hierher gehörige Fall zeigte bereits eine ausgeprägte Sehnervenatrophie (Fall 14), während der andere (Fig. 14, Fall 13) wegen eines $F$ auch nach aussen hin überragenden pericentralen absoluten Scotomes die Diagnose „Tabaksamblyopie“ zweifelhaft erscheinen liess, obwohl die rasche Verkleinerung des centralen Defectes wiederum sehr für diese Krankheit sprach.

Selbst bei dieser hochgradigen Störung der Rothempfindung ist bei der Intoxicationsamblyopie das Gesichtsfeld für weiss in seinen Aussengrenzen vollkommen normal und nur in manchen, keineswegs in allen Fällen ist aucb ein kleiner centraler Defect für weiss, also ein absolutes Scotom vorhanden, dessen Entstehung und Verlauf später noch näher betrachtet werden soll.

Schreitet die Krankheit noch weiter fort, so verschwindet schliesslich auch der letzte Rest von Rothempfindung; und es wird dann roth und grün (der Defect für letztere Farbe zeigt denselben Entwicklungsgang wie der für roth) nicht mehr erkannt, nur blau und gelb wird noch unterschieden, es ist also Rothgrünblindheit vorhanden. Diese erworbene Farbenblindheit unterscheidet sich von der angeborenen ausser in anderen Punkten noch sehr wesentlich durch die erhebliche Herabsetzung der Sehschärfe. Trotzdem sind auch diese Fälle der Besserung und wahrscheinlich vollständigen Heilung fähig. Eine derartige Rothgrünblindheit kann sehr leicht mit Sehnervenatrophie verwechselt werden, was um so eher möglich ist, als die Papille bei Intoxicationsamblyopie nicht selten weisslich verfärbt ist. Auch in unseren Journalen finden sich einige Fälle, deren Gesichtsfeld einen centralen Defect für roth bei normalen Aussengrenzen für weiss und roth zeigte, mit der Diagnose Atrophia nervi optici incipiens vor, welche sich 
lurch die spätere Wiederherstellung der vollen Sehschärfe ind des absolut normalen Gesichtsfeldes, deren unveränlertes Fortbestehen theilweise noch nach Jahren constatirt verden konnte, als unzweifelhafte Intoxicationsamblyopien rwiesen (z. B. Fall 10, Seite 40). Die vollkommen noraalen Aussengrenzen des Gesichtsfeldes für weiss, sowie lie nach absoluter Abstinenz oft schon in wenigen Tagen zintretende Besserung wird hier bald Klarheit hinsichtlich der Diagnose verschaffen. Diese ist aber in derartigen Fällen um so wichtiger, als es sich um die Unterscheidung "einer Krankheit mit sehr ungünstiger Prognose von einer solchen mit fast absolut guter Voraussage handelt.

Die erst erwähnte Form des nach innen von $F$ noch vorhandenen Gesichtsfeldrestes für roth fand sich bei dem 36 jährigen Kassenrevisor August Sch. (Fall 12). Derselbe suchte am 4. Juli 1877 die Poliklinik auf, da er eine Abnahme seiner Sehschärfe bemerkte. Die Augen boten äusserlich und ophthalmoskopisch nichts Abnormes dar. Die Sehschärfe jedes Auges betrug $20 / 100$, Sn I ${ }^{1 / 2}$ wurde noch gelesen. Das Gesichtsfeld zeigte keine Beschränkung der Aussengrenzen und keinen centralen Defect für weiss, dagegen wurde roth mit jedem Auge nur in einem beschränkten Bezirke nach innen von $F$ erkannt (Fig. 13). Der Kranke, ein kräftiger und gut genährter Mann, giebt an, früher sehr viel alcoholische Getränke; namentlich Bier zu sich genommen und täglich ein Dutzend Cigarren geraucht $\mathrm{zu}$ haben, seit einem Jahre trinkt er weniger und raucht nur etwa vier Cigarren pro Tag, schnupft aber dabei. Appetit und Schlaf sind gut, die Libido sexualis ist seit einem Jahre verringert. Die Therapie bestand ausser Abstinenz in der Darreichung von Abführmitteln und gelegentlich einem Dampfbade. Schon nach zwei Tagen zeigte das linke Auge eine Vergrösserung des Gesichtsfeldes für roth, indem nach aussen von $M$ eine kleine roth empfindende Insel auftrat. Nach neun Tagen war $\mathrm{S}={ }^{20} / \mathrm{s}_{0}$, und das Gesichtsfeld des linken Auges zeigte nur noch den bekannten eiförmigen Defect für roth, während die Aussengrenzen für diese Farbe ihre normale Ausdehnung erreicht hatten. 14 Tage nach der ersten Untersuchung hatte sich dieser Defect in zwei Hälften getheilt, deren eine an $\mathbf{F}$, die andere an $\mathbf{M}$ lag, und welche durch eine 
roth empfindende Brücke vollkommen von einander getrennt wurden. Nach einem Monat (am 3. Aug.) zeigte sich nur noch eine leichte Herabsetzung der Rothempindung in der Gegend von $F$ und nach zwei Monaten war für diese Farbe kein Defect mehr nachzuweisen, die Selschärfe betrug ${ }^{20} / \mathrm{so}$. Derselbe Befund wurde auch am 29. November notirt. Das rechte Auge zeigte eine ähnliche Rückbildung des Defectes und dieselbe Hebrng der Sehschärfe wie das linke Auge.

Vollständige anfängliche Rothgrünblindheit fand sich bei dem 33 jährigen Tischler Joseph K. (Fall 13) aus Braunau in Oesterreich. Dieser wurde am 10. Februar 1891 wegen einer seit einem halben Jahre allmälig zunehmenden Verschlechterung der Sehschärfe in die Klinik anfgenommen. Patient ist ein im Allgemeinen gesunder Mann, krankhafte Erscheinungen vou Seiten des Nervensystems sind nicht nachzuweisen, Urin frei von Zucker and Eiweiss. Der objective Befund an den Angen ist gering. Die Pupillarreaction ist träge, in der Linse sind unbedeutende Trübungen vorhanden, die Netzhaat zeigt in der Umgebung des Sehnervenkopfes eine leichte Trübung, die Pap. optic. selbst ist in ihrer temporalen Hälfte etwas blasser als in der nasalen. Die Retinalarterien sind mässig verengt, die Venen in geringem Grade erweitert. Diese Veränderungen erklären jedoch die starke Herabsetzung der Sehschärfe nicht, denn Patient zählt nur Finger bis auf $1 \mathrm{~m}$ Entfernung und liest mit $\left(+6^{\prime \prime}\right)$ mit dem rechten Auge nur kurze Worte aus Sn X, mit dem linken Auge aus Sn XVI. Erst die perimetrische Untersuchung giebt eine Erklärung für die vorhandene Amblyopie. Das Gesichtsfeld zeigt nämlich bei vollkommen normalen Aussengrenzen für weiss einen centralen absoluten Defect für diese Farbe, welcher sich anf dem linken Auge (Fig. 14) pericentrisch um $F$ herum nach allen Richtungen hin etwa $6^{\circ}$ weit erstreckt, rechts dagegen mehr paracentrisch ist und $\mathrm{F}$ nach innen hin kaum überschreitet, sich dagegen $10^{\circ}$ weit nach aussen, also nach $\mathbf{M}$ hin, erstreckt. Umgeben ist dieser absolute Defect von einer Zone von etwa $15^{\circ}$ Radius, innerhalb welcher weiss als "grau" erscheint. Rothe und grüne Quadrate selbst von $20 \mathrm{~mm}$ Seitenlänge werden in ihrer Farbe nicht erkannt. Der Kranke gab an, täglich $30-40 \mathrm{~g}$ österreichischen Tabak aus der Pfeife geraucht und $1 / 2$ Liter Korn getrunizen zu haben. Nachträgliche Erkundigungen bei seinem Bruder und seinem Hausarzte ergaben jedoch, dass er beiden Gewohnheiten in viel ausgedehnterem Maasse ergeben war. Die 
Therapie bestand in Laxantien und Abstinenz. Am folgenden Tage wurde mit jedem Auge roth in einer nach innen von $F$ gelegenen halbmondförmigen Zone erkannt (Fig. 14), welche sich am nächsten Tage bereits zu einem Ringe geschlossen hatte, der einen eiförmigen zwischen $F$ und $M$ gelegenen Defect umgab; dieses Scotom erstreckte sich von $F$ aus $18-20^{\circ}$ nach aussen und $8-10^{\circ}$ nach innen. Für das rechte Auge war ein derartiges Gesichtsfeld indessen nur bei der Untersuchung mit einem rothen Quadrate von $10 \mathrm{~mm}$ Seitenlänge $\mathrm{zu}$ erhalten, während ein Quadrat von $5 \mathrm{~mm}$ Seite nur in einem halbmondförmigen Bereiche der inneren Gesichtsfeldbälfte erkannt wurde.

Es ergeben sich also auch hier wieder bei der Untersuchung mit kleineren Quadraten oft viel ausgedehntere Gesichtsfelddefecte, als nach der Prüfung mit grösseren Objecten vorhanden zu sein scheinen, was für die Feststellung des centralen Scotoms schon längst bekannt ist.

Nach neun Tagen war der centrale Defect für roth (und auch für grün) in zwei an $F$ und $M$ gelegene Hälften zerfallen. Der centrale Defect für weiss hatte sich inzwischen ebenfalls verkleinert und hatte am 7. März, an welchem Tage Patient entlassen wurde, nur noch einen Radius von $2^{\circ}$, während für roth and grün ausser einem Scotome an $F$ auch noch eine Vergrösserung des blinden Fleckes nach oben and unten hin bestand. Die Sehschärfe hatte sich gehoben, denn der Kranke zählte mit dem rechten Auge Finger in $2 \mathrm{~m}$, mit dem linken Auge in $3^{1 / 2} \mathrm{~m}$ und las mit $\left(+6^{\prime \prime}\right)$ Sn $\mathrm{III}^{1 / 2}$ mühsam in $3^{\prime \prime}$. Die geringen ophthalmoskopischen Veränderungen an der Pap. optic. bestanden noch fort.

Nach einer briếlichen Mittheilung seitens des Hausarztes des Patienten vom 29. October, also sieben Monate später, soll sich die Sehschärfe auf Strychnininjectionen noch weiter gehoben baben, so dass der Kranke wieder als Tischler arbeiten kann.

Es mag zweifelhaft erscheinen, $o b$ es sich in diesem Falle um eine Intoxicationsamblyopie oder eine axiale retrobulbäre Neuritis gehandelt hat. Für letztere spricht nur die relativ weite Ausdehnung des Defectes für weiss nach innen zll ïber $F$ hinaus, während für erstere die rasche, 
durchaus typische Rückbildung des Defectes für roth nach streng durchgeführter Abstinenz spricht. Am wahrscheinlichsten ist die Annahme einer schwereren Form von Intoxicationsamblyopie.

Endausgang der Intoxicationsamblyopie. Der Ausgang der Intoxicationsamblyopie ist in den weitaus meisten Fällen mehr oder weniger vollständige Heilung unter Rückbildung des rorhandenen Gesichtsfelddefectes, deren Einzelbeiten noch genauer betrachtet werden sollen. In anderen Fällen bleibt der Defect stationär, es tritt weder eine Besserung noch eine Verschlimmerung des Zustandes ein, während in seltenen Fällen der Process progressiv wird und zur Sehnervenatrophie mit allmälig fortschreitender peripherer Beschränkung des Gesichtsfeldes führt.

Der letzterwähnte Ausgang der Intoxicationsamblyopie wird von einigen Ophthalmologen geleugnet, doch glaube ich denselben auf Grund mehrerer mit Wahrscheinlichkeit dafür sprechender Beobachtungen festhalten zu müssen.

Der eine dieser Fälle betrifft den 30 jährigen Maurer Gottlieb P. (Fall 14), welcher am 21. Januar 1888 die Poliklinik wegen erbeblicher Abnahme der Sehschärfe aufsuchte. Es fand sich damals im Gesichtsfelde ein eiförmiger Defect für roth, aber nicht für weiss, bei vollkommen normalen Aussen. grenzen für beide Farben (Fig. 33). Die Sehschärfe des rechten Auges war auf das Zählen der Finger in 7', des linken Auges in $5^{\prime}$ herabgesunken, mit $+6^{\prime \prime}$ wurde Sn XVI in $4^{\prime \prime}$ mühsam entziffert. Pap. opt. sehr blass. Es wurde die Diagnose auf Tabaksamblyopie gestellt, was durch die Angabe des Patienten, er kaue viel Tabak und trinke stark Schnaps, bestätigt wurde. Der Kranke will damals ein halbes Jahr lang weder gepriemt noch Schnaps getrunlen haben, woranf eine erhebliche Besserung der Sehschärfe eintrat, welche jedoch wieder einer bedeutenden Verschlechterung Platz machte, als er sich abermals dem Tabak- und Alcoholgenusse ergab. Diese Mittheilung machte uns Patient erst $2^{3} / 4$ Jahre später. Er liess sich nämlich am 22. November 1890 wegen einer Kalkverletzung des linken Auges in die Klinik aufnehmen. Die Sehschärfe, welche seitdem unverändert geblieben ist, betrug 
nach Abheilung der Conjunctival- und Hornhautverletzung, welche bis auf eine mässige periphere Trübung der linken Cornea keine nennenswerthe Spuren zurückliessen, für das rechte Auge $8 / 200$, für das linke Auge $6 / 200$, wobei mit +6 " rechts Buchstaben von SnX, links ron Sn XIII erkannt wurden. Mit dem Augenspiegel betrachtet, zeigen sich beide Papillae opticae deutlich atrophisch, sie sind weisslich verfärbt, die Netzhautarterien verengt. Zahlreiche Untersuchungen mit dem Perimeter ergeben Folgendes. Das Gesichtsfeld des rechten Auges, welches vor fast drei Jahren (Fig. 33) noch normale Aussengrenzen für weiss und roth zeigte, ist jetzt (Fig. 34) für weiss mässig, für blau stark concentrisch verengt, grün wird überhaupt nicht mehr als farbig erkannt und roth erst bei einer Grösse von $10 \mathrm{~mm}^{2}$, jedoch nur in einem halbmondförmigen, fast ausschliesslich nach innen von $F$ gelegenen Gebiete. Der ursprünglich vorhandene centrale Defect (Fig. 33) bat sich also in der geschilderten Weise zunächst nach oben und unten, dann auch nach aussen hin vergrössert, bis von der roth empfindenden Gesichtsfeldpartie nur noch innen ein kleiner Rest übrig geblieben ist. Die concentrische Verengerung der Gesichtsfeldgrenzen für weiss and blau ist eine Folge der Sehnervenatrophie. Ein centraler Defect für blau und weiss ist nicht nachzuweisen, nur erscheint letatere Farbe im Centrum des Gesichtsfeldes nicht ,weiss", sondern ,grau“. Die centrale Fixation des recbten Auges ist aufgehoben, so dass mall den Kranken einen $8^{0}$ nach innen von $\mathrm{F}$ gelegenen Punkt fixiren lassen muss, damit die Gesichtslinie auf $F$ gerichtet ist.

Das Sehfeld des linken Auges (Fig. 35) zeigt für weiss eine noch stärkere concentrische Einengung als das des rechten Auges, ebenso für blau, wobei jedoch zu berücksichtigen ist, dass ein blaues Object von $10 \mathrm{~mm}$ Seitenlänge benutzt werden musste, da ein solches von $5 \mathrm{~mm}$ Seite nicht mehr deutlich in seiner Farbe erkannt wurde, es erscheinen hierdurch die Aussengrenzen für blau anscheinend weiter zu sein, als auf dem rechten Auge, für dessen Untersuchnng das kleinere blaue Quadrat Verwending fand. Roth $\left(20 \mathrm{~mm}^{2}\right)$ wird nur in einer schmalen, hauptsächlich in der inneren Gesichtsfeldbälfte gelegenen sichelförmigen Zone erkannt, grün überhaupt nicht mehr farbig gesehen. Auch dieses Auge zeigt keinen absoluten Defect für weiss and kein centrales Scotom für blau.

Es dürfte kaum zu bezweifeln sein, dass es sich in diesem 
Falle um den Uebergang der anfänglich beobachteten Intoxicationsamblyopie in Sehnervenatrophie handelt.

Auffallend und vielleicht für diese Form der Sehnervenatrophie characteristisch ist es, dass trotz des ausgedehnten Defectes für roth und grün, sich für blau and weiss kein centrales Scotom findet, wälrend die Aussengrenzen des Gesichtsfeldes schon eine starke Einengung zeigen. Das Sehvermögen wird also viel mehr durch die centripetal fortschreitende Verkleinerung des Gesichtsfeldes, als durch die Vergrösserung des centralen Defectes und dessen Uebergang aus einem relativen in einen absoluten bedroht. Es geht dies auch daraus hervor, dass der centrale Defect der Intoxicationsamblyopie als solcher für immer unverändert bestehen bleiben kann, ohne irgend eine Neigung zum Fortschreiten zu zeigen.

Dieses Stationärbleiben des Defectes ist der zweite Ausgang, welchen die Intoxicationsamblyopie nehmen kann, wenn ihr nicht bei Zeiten Einhalt gethan wird. Die bierher gehörigen Fälle kommen gewöbnlich unter dem ophthalmoskopischen Bilde einer Sehnervenatrophie zur Beobachtung, doch zeigt das Gesichtsfeld vollkommen normale Aussengrenzen und einen centralen Defect für roth, aber nicht für weiss, von der characteristischen Eiform. Es erscheint immerhin auffallend, dass nur der centrale ovaläre Defect sich dauernd erhält und nicht durch weiteres Wachsthum mindestens das Gebiet der Roth- und Grünempfindung rollkommen vernichtet. Indessen ist dieses Gebiet auch nicht vollkommen normal, vielmehr zeigt bei allen derartigen Kranken eine sorgfältige Untersuchung eine Störung auch des peripheren Farbensinnes für roth und grün, indem diese Farben oft erst an grösseren Objecten richtig erkannt werden. Ausserdem ist die Schädigung der mehr peripheren Gesichtsfeldpartien bei der Tabaksamblyopie immer viel geringer, als diejenige des Centrums, der pathologische Process klingt nach der Peripherie hin ab, 
so dass bei eintretender Abstinenz - einmal werden wohl alle derartigen Kranken wenigstens relative Abstinenz üben - die wenig alterirten mehr peripheren Gesichtsfeldpartien sich noch leidlich erholen können, trotzdem die centrale Sehstörung bereits irreparabel geworden ist.

Als Beispiel sollen zwei derartige Fälle dienen. Der 42 jährige Einlieger Robert R. (Fall 15) wurde am 19. November 1890 in die Klinik aufgenommen, da er seit $2^{1 / 2}$ Jahren eine allmählige Abnahme der Sehschärfe beider Augen bemerkte, welche ihm seit einem viertel Jahre das Lesen gewöhnlicher Druckschrift unmöglich macht. Patient rancht und trinkt sehr viel. Cerebrale und spinale Veränderungen fehlen, Patellarreflexe vorhanden. Augen äusserlich normal. Die Sehnervenpapillen sind besonders in der temporalen Hälfte stark weisslich verfärbt, während die nasalen Partien noch einen geringen röthlichen Ton zeigen, Netzhautarterien eng. Mit jedem Auge werden noch Finger bis auf $2 \mathrm{~m}$ Entfernung gezählt und mit $\left(+6^{\prime \prime}\right)$ werden rechts von Sn XIII, links von Sn X noch Buchstaben erkannt. Das Gesichtsfeld (Fig, 31 und 32) zeigt für weisse, blaue und rothe Quadrate von $5 \mathrm{~mm}$ Seitenlänge normale Aussengrenzen, während grüne Quadrate selbst bei $10 \mathrm{~mm}$ Seite nicht in ibrer Farbe erkannt werden. Ausserdem ist ein centraler Defect von der für die Tabaksamblyopie charakteristischen Form vorhanden. Innerhalb dieses Scotoms erscheint roth als "grau", verschwindet aber nicht vollkommen, während blau und weiss richtig erkannt werden. Patient wurde einer Abführcur mit vollkommener Abstinenz unterworfen. Als er nach vier Wochen die Klinik verliess, war sein Zustand noch vollkommen unverändert.

Der zweite derartige Fall betraf den 39 jährigen Hermann B. (Fall 16), welcher am 25. November 1889 in die Klinik aufgenommen wurde. B., der Sohn eines Arztes, hat ein reichbewegtes Leben hinter sich. Gelernter Gärtner, trat er in holländische Militärdienste und war 1882-1888 auf Java, wo er im August 1884 eine ziemlich rasch eintretende Verschlechterung des Sehens bemerkte, welche seitdem unverändert bestehen geblieben ist. Der Kranke ist eingestandenermaassen Potator, rauchte früher sehr stark and consumirt auch jetzt noch täglich 5-6 Cigarren; er ist ein kräftiger Mann. Zeichen von Lues oder Erkrankungen des Nervensystemes 
fehlen. Die Augen bieten äusserlich nichts auffallendes dar, dagegen zeigt der Augenspiegel die Papillen, besonders auffallend in der äusseren Hälfte weisslich verfärbt, die Netzhautgefässe von normalem Caliber, an der Maculagegend nichts pathologisches. $S={ }^{20} / 200$, mit +6 " werden in $3^{\prime \prime}$ mit dem rechten Auge von Sn III, mit dem linken Avge von Sn III $^{1} / 2$ kurze Worte gelesen. Das Gesichtsfeld (Fig. 36) zeigt normale oder fast normale Aussengrenzen für weiss und einen centralen Defect für roth, der auf dem rechten Auge die bekannte Eiform hat, auf dem linken Auge aber nach aussen und aussen oben die Grenze der Rothempfindung darchbrochen hat. Von den zur Perimeteruntersuchung benatzten farbigen Quadraten werden in 1' Entfernung gelb und blau bei $5 \mathrm{~mm}$, grụ̈ und roth aber erst bei $10 \mathrm{~mm}$ Seitenlänge richtig erkannt. Auf der Daae'schen Tafel bezeichnet Patient die Reihen 8 und 10 (blau, rosa und violett, resp. blau und purpor) als gleichfarbig. Nach dreiwöchentlicher, in Strychnininjectionen bestehender Behandlnng, verliess der Kranke ohne Besserung seines Zustandes die Klinik. Auch in diesem Falle handelt es sich um einen seit fünf Jahren stationär gebliebenen centralen Defect nach Tabaksamblyopie. Trotzdem man nach dem Augenspiegel eine Sehnervenatrophie annebmen möchte, zeigt doch der Process keine Neigung zum Fortschreiten, wie die normalen Aussengrenzen des Gesichtsfeldes beweisen.

Neben diesen zum Glück sehr seltenen und nur in ganz vernachlässigten Fällen vorkommenden beiden schlimmen Ausgangsformen der Tabaksamblyopie wird als dritte bei weitem häufigste der Uebergang in Heilung beobachtet. Eine solche ist in allen nicht gar zu lange bestehenden Fällen bei Durchführung vollkommener Abstinenz möglich. Natürlich haben sich die Kranken zum Theil unserer Beobachtung entzogen, oft aus äusseren Gründen, oft aber auch, weil sie nicht die nöthige moralische Kraft zur Entsagung besassen. Briefliche Erkundigungen bei derartigen Flïchtlingen haben dann oft genug ergeben, dass sich die Sehschärfe bei vollkommener Entsagung erheblich gehoben hatte.

Rückbildung des Defectes für roth. Die Rückbildung des Defectes für roth erfolgt genau in derselben 
Weise wie seine Entstehung. Ist also die Rothempfindung vollkommen verschwunden - auch derartige Fälle sind noch der Heilung fähig, wie ein bereits oben citirtes Beispiel zeigt - so tritt zunächst in der inneren Gesichtsfeldhälfte eine roth empfindende Stelle auf, später zeigt sich eine eben solche Insel nach aussen von M. Beide vergrössern sich und vereinigen sich zunächst unten, später auch oben durch eine Brücke, wodurch das bekannte Gesichtsfeld für roth mit dem centralen ovalären Defecte entsteht. Dieser Defect theilt sich in zwei Hälften, eine an $\mathrm{F}$ und eine an $\mathrm{M}$ gelegene, beide werden allmälig kleiner und verschwinden schliesslich vollständig, so dass nur noch der normale blinde Fleck zurückbleibt. Diese Rïckbildung geht oft innerhalb weniger Tage vor sich, es giebt keine Gesichtsfeldveränderung, welche einen so raschen Rückgang zeigte, wie manchmal der Defect bei der Tabaksamblyopie. Gerade an diesen abheilenden Fällen lässt sich die Genese des Defectes sehr gut studiren, da man denselben in kurzer Zeit alle uiberhaupt vorkommende Stufen durchlaufen sehen kann, während uns gewisse Stadien desselben bei der Beobachtung an frisch Erkrankten nur selten zu Gesichte kommen. Die Besserung der Sehschärfe hält mit der Rückbildung des Defectes meist nicht gleichen Schritt, sondern folgt ihr erst später nach.

Als Beispiel für die Rückbildung grösserer Defecte können die Figuren 3 und 4 (Fall 5), 11 und 12 (Fall 10), sowie 16-19 (Fall 11), und ferner das bei der Beschreibung der Figuren 13 und 14 (Fall 12 und 13) gesagte dienen. Hier sollen nur noch zwei Fälle genauer beschrieben werden, welche den typischen Verlauf des Defectes illustriren.

Der erste betrifft den 38 jährigeu Weber Gustav St. (Fall 17), welcher am 1. Juni 1876 wegen hochgradiger Amblyopie die Poliklinik aufsuchte. Die Sehschärfe zeigt sich stark herabgesetzt, ohne Glas wird nur Sn III von $5-7^{\prime \prime}$ und 
mit $\left(+10^{\prime \prime}\right)$ Sn II gelesen. Das Gesichtsfeld des rechten Auges zeigt einen eiförmigen Defect für roth und grün zwischen $F$ und M bei normalen Aussengrenzen (Fig. 20), das des linken Auges bietet ganz ähnliche Verhältnisse dar. Ausserdem ist an $\mathbf{F}$ ein kleiner, nur in der äusseren Gesichtsfeldhälfte gelegener Defect für weiss vorhanden. Patient giebt an, täglich etwa $35 \mathrm{~g}$ Tabak zu rauchen, aber nur wenig Schnaps zu trinken. Der Appetit ist gering, der Schlaf besonders in der letzten Zeit schlecht. Es wurde die Diagnose auf Tabaksamblyopie gestellt und dem Kranken Abstinenz empfohlen, worauf eine bedeutende Besserung eintrat. Am 17. Juni betrug nämlich $S=20 / 100$, und der Defect für roth hatte auf dem rechten Auge eine hufoisenförmige Gestalt angenommen, indom er durch eine von oben her in ihn hineinragende normal functionirende Halbinsel eingebuchtet wurde (Fig. 21), der an F liegende Theil des Defectes war noch absolut. Auf dem linken Auge zeigte sich innerhalb des eiförmigen Defectes unmittelbar nach innen von M eine roth empfindende Insel, auch auf diesem Auge war noch ein Defect für weiss vorhanden. 11/3 Monate später (16. August) war $S$ auf $20 ! 50$ gestiegen, und es bestand nur noch an $F$ in der Richtung auf $M$ zu ein kleiner Defect für roth (Fig. 22), während ein absoluter Defect nicht mehr nachzuweisen war. Weitere Nachrichten über den Patienten liegen nicht vor. Das langsame Fortschreiten der Besserung erklärt sich eines Theils aus der durch das Auftreten eines Defectes für weiss documentirten Schwere der Erkrankung, andererseits aber höchst wabrscheinlich auch noci dadurch, dass der nur ambulant behandelte Kranke das Rauchen aicht vollkommen unterliess, sondern nur einschränkte.

Einen ähnlicheu Verlauf zeigte die Erkrankung des 35 jährigen Tischlers Johann A. (Fall 18), welcher am 18. Decbr. 1890 in die Klinik aufgenommen wurde. Patient bemerkte seit Pfingsten dieses Jahres eine allmälige Abnabme der Sehschärfe. Bei heller Beleuchtung sah er schlechter als bei gedämpfter, weshalb er sich zu seiner Arbeit einen dunkleren, vom Fenster möglichst entfernten Platz answählte. Anfangs gab Patient an, nur wenig zu trinken und zu rauchen, erst nach drei Wochen, als seine Krankheit schon eine erhebliche Besserung aufwies, bequemte er sich zu dem Geständniss, täglich $1 / 2$ Liter Schnaps zu consumiren, $35 \mathrm{~g}$ schweren Presstabak aus der Pfeife und noch 2-3 Cigarreu ausserdem zn ranchen, sowie zu schnupfen. Die Untersuchung der Augen ergiebt ausser 
einer Abblassung des temporalen Papillenquadranten nichts pathologisches.

Rechtes Auge: $\mathrm{S}=$ Finger in $5 \mathrm{~m}$ gezählt; $(+6)$ Sn $\times \mathrm{kl}$. Linkes $\quad, \quad S=$ Finger in $2 \mathrm{~m}$ gezählt; $(+6)$ Sn XVI kl. Das Gesichtsfeld zeigt. normale Aussengrenzen für weiss and roth und einen Defect für roth zwischen F und M, diese Farbe verschwindet daselbst nicht vollständig, sondern erscheint nur dunkler, für grün ist ein ähnliches relatives Scotom vorhanden. Bereits nach zwei Tagen zeigte der Defect des rechten Auges (Fig. 23) eine Unterbrechung durch eine von unten aussen hineinragende roth empfindende Partie, nach drei Tagen war er bereits in zwei Hälften zerfallen (Fig. 24), nach sechs Tagen (Fig. 25) war nur noch ein ganz kleiner Defect an $F$ und eine geringe Vergrösserung des blinden Fleckes vorhanden, nach 11 Tagen war auch mit kleinen rothen und grünen Objecten kein pathologischer Defect mehr nachzuweisen. Der Defect des linken Auges war nach vier Tagen in zwei Theile zerfallen, nach sechs Tagen (Fig. 26) zeigte sich nur noch ein kleiner Defect an F, während der blinde Fleck nach unten hin einen flügelförmigen Fortsatz hatte. Letzteres Scotom war zum grössten Theil auch für roth nur relativ, $d . h$. diese Farbe erschien daselbst dunkler, und verschwand nur in einem kleinen Bereiche vollkommen. Nach 11 Tagen war joder Defect an F, nach 13 Tagen auch die Vergrösserung des blinden Fleckes verschwunden. $S$ hatte sich unterdessen auch geloben und zwar wahrscheinlich auf $20 / 40$, wenigstens liess sich diese Sebschärfe dann und wann einmal ron dem Kranken durch gutes Zureden berauspressen. Patient machte nämlich jetzt, betreff seiner Sehschärfe, die widersprechendsten Angaben, so dass wir die Ueberzeugung erlangten, er simuliere eine viel stärkere Amblyopie, als vorhanden war, um noch einige Wochen auf Kosten der Krankenkasse verpflegt zu werden.

Der in diesem Falle vorhandene flügelartige Fortsatz des blinden Fleckes nach unten (Fig. 26) findet sich im Anfangs- und Endstadium des Defectes nicht selten. Oefter treten auch zwei solche Fortsätze, einer nach oben und einer nach unten hin gerichtet, auf.

Defect für weiss. Wie schon mehrfach erwähnt, ist bei der Intoxicationsamblyopie meist nur ein centraler Defect für roth vorhanden, doch kommt auch ein solcher für 
weiss vor, so dass das Scotom dann in einem kleinen Theile zu einem absoluten wird. Derartige Fälle sind immer als eine schwerere Erkrankungsform anzusehen und brauchen zu ihrer Rückbildung längere Zeit als diejenigen, welche nur einen relativen Defect aufweisen. Das absolute Scotom hat eine durchaus characteristische Entstehung und Rückbildung, es ist nicht constant, sondern wird selbst bei grossen Defecten für roth vermisst, ja, sogar wenn roth iberhaupt nicht mehr erkannt wird, braucht noch kein Defect für weiss vorhanden zu sein, während umgekehrt der Defect für weiss den für roth manchmal an Grösse fast erreicht. Es besteht also kein bestimmtes Verhältniss zwischen beiden Defecten, ausser in der Hinsicht, dass ein absoluter Defect überhaupt erst dann auftritt, wenn das Scotom für roth eine gewisse Ausdehnung, mindestens die Grösse eines zwischen $\mathbf{F}$ und $\mathbf{M}$ sich erstreckenden Ovales erlangt hat. Bei der Rückbildung des Defectes finden sich freilich auch kleinere Scotome für roth, von denen ein Theil noch absolut ist (z. B. Fig. 30). Es darf bei der Beurtheilung der ganzen Frage nicht vergessen werden, dass es manchmal schwer ist $\mathrm{zu}$ constatiren, ob ein Scotom in einem gewissen Bezirke wirklich absolut ist, wenigstens so weit es sich um die Perimeteruntersuchung handelt. Das weisse Prüfungsobject erscheint nämlich innerhalb des Defectes für roth in seiner Helligkeit vermindert, es wird „grau“. Bei wenig intelligenten Kranken ist es demnach manchmal nicht mit Sicherheit zu eruiren, $o b$ das weisse Quadrat an einer Stelle schwarz erscheint, also vollkommen verschwindet, oder ob es nur "grau" wird. Auch ist eine Netzhautpartie, die wir auf Grund dieser Untersuchungsmethode als "absolut defect" bezeichnen, sicher oft nicht in dem Sinne blind, wie etwa der Mariotte'sche Fleck oder die Netzhautperipherie, sondern sie ist nur für die angewandten schwächeren Reize wenig oder gar nicht empfindlich, durch stärkere aber noch erregbar. Es ist sicher 
constatirt, dass in einigen Fällen, welche sich durch Aetiologie und Verlauf als Intoxicationsamblyopie characterisirten, ein kleiner absoluter Defect vorhanden war. Auch diejenigen noch genauer zu schildernden Fälle, bei welchen ein grösserer Theil des Scotomes absolut ist und trotzdem eine verhältnissmässig rasche Rückbildung desselben orfolgt, gehören wohl zur Intoxicationsamblyopie und nicht zur axialen Neuritis, da auch alle sonstigen Allgemeinsymptome der Tabaksvergiftung vorhanden sind. Jedenfalls baben diese Fälle eine bedeutend günstigere Prognose, als sie für die Neuritis axialis im Allgemeinen angenommen wird. Indem ich nochmals betone, dass vielleicht eine Anzahl Kranker einen absoluten Defect angiebt, wo nur ein hochgradiger relativer vorhanden ist, und dass demgemäss der absolute Defect bei der Intoxicationsamblyopie möglicherweise seltener ist, als es nach meinen Beobachtungen scheint, will ich nun zur genauen Schilderung dieses Defectes übergehen.

Im Anfangsstadium der Tabaksamblyopie ist ein Defect für weiss niemals vorhanden, derselbe tritt vielmehr erst auf, sobald das Scotom für roth die Form eines sich zwischen $\mathrm{F}$ und $\mathrm{M}$ erstreckenden Ovales erlangt hat. Dann zeigt sich in einzelnen Fällen an $F$ und zwar nach aussen hin ein kleiner absoluter Defect von etwa $5^{\circ}$ Durchmesser (Fig. 4, 20, 21 und 30), welcher $\mathrm{F}$ nach innen hin wenig oder gar nicht überschreitet. Dehnt sich der absolute Detect auch nach innen von $F$ aus, so dass ein pericentrales, sich von $F$ aus nach allen Richtungen hin ungefähr gleichweit erstreckendes Scotom entsteht, so ist der Verdacht begründet, dass es sich um eine Neuritis axialis handelt. Gleichzeitig mit dem Defecte an F tritt häufig eine Vergrösserung des blinden Fleckes für weiss in der Richtung nach $\mathrm{F}$ zu auf, auch kommt der letztere Defect allein vor, ohne dass ein absolutes Scotom an $\mathrm{F}$ vorhanden ist. Beide Scotome wachsen genau in derselben Weise, wie dies von dem Defecto für roth bereits geschildert worden ist; und 
vereinigen sich schliesslich durch eine Brücke, welche oberhalb, unterhalb oder in der Verbindungslinie ron $F$ und $M$ gelegen sein kann (Fig. 29). Endlich bekommt der Defect die bekannte Form eines sich zwischen $F$ und $M$ erstreekenden Ovales, ist aber stets kleiner als der Defect für roth und zwar mindestens um etwa $5^{\circ}$, nur nach aussen von $\mathrm{M}$ beträgt die Differenz circa $2^{\circ}$. Ein weiteres Wachsthum des Defectes für weiss habe ich bei der Intoxicationsamblyopie nicht beobachtet. Verkleinert sich der Defect für roth, so geht ihm eine Verkleinerung des Defectes für weiss voran, der letztere zerfällt in zwei Theile, genau ebenso wie das Scotom für roth bei seiner Rüekbildung, durch oine von oben oder unten zwischen $F$ und $M$ in den Defect hineinwachsende Halbinsel, oder innerhalb des Scotomes auftretende wieder weiss empfindende Insel, welche sich allmälig vergrössert. Die beiden Hälften des Scotomes, deren eine an $\mathrm{F}$, die andere an $\mathrm{M}$ liegt, verkleinern sich schliesslich soweit, dass nur noch der normale blinde Fleck übrig bleibt. Sobald der Defect für weiss eben verschwunden ist, bleibt stets noch ein Defect für roth zurïck, der crst später verschwindet.

Das Auftreten eines absoluten Scotomes innerhalb des Vefectes für roth bezeichnet eine schwerere, weiter fortgoschrittene Form der Intoxicationsamblyopie, indem dic Riuckbildung dann längere Zeit in Anspruch nimmt und die Selıschärfe stärker herabgesetzt ist, als beiw Vorhandensoin eines einfachen Farbenscotomes. Doch sind auch derartige Fälle der vollkommenen Heilung bis zum Verschwinden jedes Defectes für weiss und roth und Herstellung guter Sehschärfe fähig.

Die geschilderten Verhältnisse des Defectes für weiss zcigen die Figuren 3 und 4, dem rechten Ange des 38 jährigen Kutschers August W. (Fall 5) entuommen. Ueber das Gesichtsfeld des linken Auges (Fig. 2) ist bereits berichtet worden. Das rechte Auge zeigte am 13. Juni 1883 einen nach oben hin 
durchgebrochenen Defect für roth (Fig. 3) und innerhalb desselben einen eiförmigen Defect für weiss, die Sehschärfe war auf das Zählen der ausgestreckten Finger $1 \frac{1 / 2}{\mathrm{~m}}$ herabgesetzt. Vier Wochen später hatte sich die Sehschärfe desselben Auges auf $2 \% /_{100}$ gehoben, für roth war nur noch ein ovaler Defect vorhanden, und der Defect für weiss war bereits in zwei getrennte Partien, eine an $F$ und eine an $M$ gelegene, zerfallen (Fig. 4), die Aussengrenzen des Gesichtsfeldes für weiss waren stets normal. Weitere Nachrichten über den Verlanf der Krankheit fehlen.

Die Figuren 20-22 (Fall 17) zeigen ebenfalls das Verschwinden des Defectes für roth und weiss.

Ein anderes derartiges Beispiel zeigt das dem linken Auge des 42 jährigen Schmiedes Theodor R. (Fall 19) entnommene Gesichtsfeld (Fig. 28-30). Patient stellte sich am 24. October 1876 mit der Angabe vor, dass er seit dem Juni eine $\mathrm{Ab}$ nahme seines Sehvermögens bemerkt habe. Der Kranke trinkt wenig Schnaps, viel einfaches Bier und raucht schon seit seinem 7. Lebensjahre stark Pfeife und zwar sehr kräftigen amerikanischen Presstabak. In der letzten Zeit machte er einen chronischen Gelenkrheumatismus durch und war $3 / 4$ Jahre lang arbeitslos, was ihm viel Kummer bereitete. $S=2 \%$, mit $\left(+10^{\prime \prime}\right)$ wird mit dem rechten Ange Sn $I^{1} / 2$, mit dem linken Ange Sn III gelesen. Das Gesichtsfeld ergiebt einen centralen Defect von Eiform für blau, roth und grün und einen nur wenig kleineren für weiss (Fig. 28), bei normalen Aussengrenzen für diese Farben. Dem Kranken wurde Abstinenz empfohJen, worauf sich $S$ innerhalb acht Tagen auf $20 / 70$ hob und Patient ausserordentlich starken Appetit bekam. Der Stuhlgang war jetzt retardirt, weshalb Laxantien verordnet wurden. Patient erschien erst wach mehreren Wochen, am 1. December wieder und zwar in sehr reducirtem Zustande, er hatte sich augenscheinlich wieder dem Trunke ergeben. $S={ }^{20} / 200$, nach sechs Tagen bereits ${ }^{20} / 100$, zur selben Zeit zeigt das Gesichtsfeld einen ovalen Defect für roth; und innerhalb desselben auch einen Defect für weiss, welcher auf dem rechten Auge, ähnlich wie in Figur 20, nur die Gegend von $\mathbf{F}$ in der Richtung nach $\mathrm{M}$ hin sich $5^{0}$ weit erstreckend, einnimmt, während er links (Fig. 29) eine Beutelform hat. Diese entsteht dadurch, dass die Theilung des Defectes in zwei Hälften, eine an $F$ and eine an $\mathbf{M}$ gelegene, bereits angedeutet ist, beide aber 
noch durch eine horizontale - fünf Tage später verschwundene - Brücke mit einander verbunden sind. Da Patient in der Nacht nur wenig, oft kaum zwei Stunden lang, schläft, so erhält er drei Tage lang Abends je $1 \mathrm{~g}$ Chloralhydrat, worauf die Agrypnie danernd verschwindet. 19 Tage später (20. Decbr.) beträgt die Sehschärfe jedes Auges $2 \% 30$, das Gesichtsfeld zeigt noch eine bedeutende Vergrösserung des blinden Fleckes und einen Defect für roth und grün unmittelbar an F, welcher für das linke Auge (Fig. 30) noch innerhalb eines kleinen Bereiches absolut ist, was rechts nicht der Fall ist. Nach weiteren zwei Wochen (4. Januar 1877) ist auf dem rechten Auge für roth überhaupt kein Defect mehr nachzuweisen, auf dem linken nur noch ein ganz kleiner unmittelbar an $\mathrm{F}$.

Während bei dem eben erwăhnten Patienten der Defect sehr rasch verschwand, zeigte er in dem folgenden Falle, nämlich bei dem 37 jährigen Tagarbeiter Anton Gl. (Fall 20) einen sehr langsamen Rückgang. Patient suchte am 12. März 1876 die Poliklinik auf. Es wurde damals notirt: Hat täglich fünf Pfeifen schlechten Tabak geraucht und für neun Pfennige Schnaps getrunken, isst nur selten Fleisch. Pap. opt. sehr blass. Rechtes Auge: $\mathrm{S}=$ Finger in $10^{\prime}$; Sn IV kl. einzelne Buchstaben. Linkes Auge: $\mathrm{S}=$ Finger in $5^{\prime}$; Sn XX kl. Das Gesichtsfeld zeigt bei normalen Aussengrenzen für roth und weiss einen eiförmigen Defect für beide Farben (Fig. 27), welcher einen Monat später noch unverändert bestand, trotzdem sich die Sehschärfe inzwischen etwas gehoben hatte. Nach vier Monaten (22. Juli) war der Defect für roth noch unverändert, derjenige für weiss aber bereits in zwei Theille, einen an $F$ und einen an M gelegenen, zerfallen und die Sehschärfe des rechten Auges betrug 20/70, die des linken Auges 20/100. Nach weiteren zwei Monaten (16. Sept.) war im Gesichtsfelde kein Defect mehr nachzuweisen, die Sehschärfe betrug $20 / 30$ und es wurde Sn I1/2 gelesen. Da der Kranke im Gegensatze zu dem vorigen nur poliklinisch behandelt wurde, so ist die langsame Besserung möglicher Weise auf das nicht vollkommen stricte Innehalten der empfohlenen Abstinenz za schieben.

Differentialdiagnose. Da bei der Intoxicationsamblyopie in einzelnen Fällen ein Defect für weiss vorhanden ist, so muss hier noch der Differentialdiagnose gegenüber der Neuritis retrobulbaris axialis gedacht werden. Nur 
diese Krankheit kommt in Betracht, da die durch Chorioideal- und Retinalkrankheiten bedingten centralen Scotome stets von derartigen characteristischen ophthalmoskopischen Erscheinungen begleitet sind, dass eine Verwechslung derselben mit dem Defecte der Intoxicationsamblyopie nicht zu befürchten ist. Die übrigen durch toxische Stoffe, z. B. Blei, bedingten Amblyopien, soweit sie überhaupt mit einem centralen Scotome einhergehen, verlaufen nach den bisherigen noch wenig zahlreichen Beobachtungen meist unter dem Bilde der Neuritis axialis. Auch bei Diabetes mellitus kommt ein ähnliches Scotom vor, das sehr hartnäckig ist. Das bei der retrobulbären Neuritis vorkommende Scotom hat eine grosse Aehnlichkeit mit dem der Tabaksamblyopie. Unter der Voraussetzung, dass auch die geschilderten mit einem grösseren absoluten Scotome verlaufenden Fälle zur Intoxicationsamblyopie zu zählen sind, bestehen folgende Unterschiede im Gesichtsfeldbefunde bei dieser Krankheit und der retrobulbären axialen Neuritis.

1) Ist nur ein Defect für roth, aber nicht für weiss vorhanden, so handelt es sich wahrscheinlich um eine Intoxicationsamblyopie. Nur wenn der Defect für roth noch klein ist, können Zweifel entstehen, ob derselbe nicht als erstes Stadium einer Neuritis axialis anzusehen ist und sehr bald zu einem absoluten werden wird.

2) Wenn bei vorhandenem Defect für weiss der Defect für roth wenigstens die Grösse eines sich zwischen $F$ und $\mathbf{M}$ erstreckenden horizontalen Ovales erreicht hat, oder noch grösser ist, so kann sowohl retrobulbäre Neuritis, als auch Intoxicationsamblyopie vorhanden sein. Hat dagegen der Defect für beide Farben annähernd dieselbe Grösse and beschränkt sich auf die Gegend von $F$, ohne $\mathrm{M}$ zu erreichen, so handelt es sich - ausser in dem leicht $\mathrm{zu}$ constatirenden Falle, einer in der Rückbildung begriffenen Intoxicationsamblyopie (Fig. 30) - mit grosser Wahrscheinlichkeit um eine Neuritis axialis. 
3) Bei der Intoxicationsamblyopie erstreckt sich der Defect von $\mathrm{F}$ aus meist nach aussen hin auf $\mathrm{M}$ zu und überschreitet $\mathrm{F}$ in der Regel nur wenig oder gar nicht nach innen, während das Scotom der axialen Neuritis stets absolut ist und $\mathrm{F}$ auch nach innen hin oft beträchtlich überragt, ehe es den blinden Fleck erreicht.

4) Periphere Verengerungen des Gesichtsfeldes für weisse oder farbige Objecte, namentlich einspringende Winkel, sprechen für retrobulbäre Neuritis. Die bei Intoxicationsamblyopie vorkommende Sehnervenatrophie braucht wohl kaum differentialdiagnostisch in Betracht gezogen zu werden, da sie exst nach jahrelang bestehender Amblyopie eintritt.

Es giebt also Fälle, in welchen man namentlich bei der ersten Untersuchung zwischen Intoxicationsamblyopie und Neuritis retrobulbaris schwanken kann, indessen werden sich dieselben bei weiterer Beobachtung klarstellen lassen, da bei geeigneter Behandlung die Intoxicationsamblyopie meist sehr bald die characteristische Rückbildung des Defectes, oder doch wenigstens keine Vergrösserung desselben zeigt, die Neuritis retrobulbaris nicht selten trotz aller Therapie fortschreitet.

Abgesehen von dem Gesichtsfeldbefunde dienen noch andere Momente zur Unterscheidung beider Krankheiten. Die Amblyopia ex abusu Nicotianae et Spirituosorum befällt meist ältere Leute, welche die Allgemeinsymptome der chronischen Tabaksintoxication zeigen, sie entwickelt sich allmälig und ergreift beide Augen gleichzeitig, während die Neuritis axialis meist junge Leute inmitten des besten körperlichen Wohlbefindens betrifft, nicht selten ganz plötzlich einsetzt und häufig zuerst auf einem Auge auftritt. Dass die Intoxicationsamblyopie bei fortgesetzter Einwirkung des schädlichen Agens den Verlauf der retrobulbären Neuritis annehmen kann, habe ich nie gesehen. Man müsste denn gerade die Fälle von Intoxicationsamblyopie, welche in 
Sehnervenatrophie übergehen, zur retrobulbären Neuritis rechnen.

Ueber die in Abstinenz und Hebung des Allgemeinbefindens bestehende Therapie wäre nur allgemein Bekanntes zu berichten.

Sitz des pathologischen Processes. Wo sind die pathologisch-anatomischen Veränderungen, welche bei der Intoxicationsamblyopie vorliegen, localisirt?

Es sind drei Fälle möglich, entweder der Process befällt direct oder indirect die Licht percipirenden Elemente, also die Netzhaut, oder er ergreift die zur Fortleitung der Lichtempfindung bestimmten Nervenfasern, also Sehnerv, Chiasma oder Tractus opticus, oder endlich, er hat seinen Sitz in den Centralorganen, der Hirnrinde. Die erste Ansicht wurde von $\mathrm{Baer}$ vertreten, welcher dieselbe jedoch wieder verlassen hat. Er nimmt eine durch das Nicotin bedingte Contraction der Netzhautgefässe an, welche secundär zu einer Ernährungsstörung der Netzhaut, speciell der lichtempfindenden Elemente, führt. Diese Annahme würde indessen nur das Entstehen des ovalen Defectes erklären, nicht aber dessen weiteres Fortschreiten, ganz abgesehen davon, dass ophthalmoskopisch eine Veränderung in dem Caliber der Netzhautgefässe nicht zu constatiren ist. Der centrale Sitz der Affection ist u. a. von Filehne behauptet worden, dann mïsste aber das Scotom an identischen und nicht an symmetrischen Stellen des Gesichtsfeldes auftreten. Filehne hat nun zwar während seiner Erkrankung auf seinem linken Auge einen dem blinden Flecke des rechten Auges entsprechenden Defect im Sehfelde constatiren können, indessen steht diese Beobachtung vollkommen isolirt da. Trotz mehrfacher darauf hingerichteter. Untersuchungen ist es mir nie gelungen, ein derartiges identisches Scotom nachzuweisen. Es bleibt also nur noch die Möglichkeit übrig, den Process in die Leitungsbahnen zu verlegen. Hierfür spricht der Augenspiegelbe- 
fund, Abblassung der temporalen Papillenhälfte, ferner die Besserung der Sehschärfe bei gedämpfter und die Verschlechterung bei heller Beleuchtung, ein Symptom das nach Förster den Krankheiten der leitenden Fasern zukommt, endlich aber beweisen die bisherigen Sectionsbefunde mit aller Bestimmtheit, dass der Process nur im Sehnerven sitzen kann. Denn die Thatsache, dass der bekannte eiförmige Gesichtsfelddefect durch eine in einer bestimmten Fascrgruppe beider Sehnerven zu gleicher: Zeit auftretende Erkrankung bedingt wird, ist nach den vollkommen übereinstimmenden Sectionsbefunden nicht mehr zu leugnen. Es ist dadurch auch gleichzeitig endgültig entschieden, dass der primäre Sitz der Erkrankung im Sehnerven, und nicht im Chiasma oder Tractus opticus zu suchen ist, indem in einigen Fällen die Veränderungen sich nur in dem orbitalen Theile des Sehnerven fanden, den intracraniellen und das Chiasma aber überhaupt nicht erreichten.

Worauf beruht das eigenthïmliche, nach den verschiedenen Richtungen hin ungleichmässige und doch so streng gesetzmässige Wachsthum des centralen Gesichtsfelddefectes? Da wir als Ursache für das Scotom einen Process im Sehnerven verantwortlich machen, so kann das Wachsthum des Defectes auch nur auf einer weiteren Ausbreitung der Sehnervenerkrankung beruhen. Diese Ausbreitung muss in durchaus gesetzmässiger Weise erfolgen, indem, wie der Gesichtsfelddefect lehrt, die einzelnen Nervenfaserbündel stets in ganz bestimmter Reihenfolge ergriffen werden. Sollten wir also durch einige glückliche Sectionsbefunde ins Klare kommen, an welcher Stelle die Sehuervenerkrankung beginnt und wie sie sich weiter verbreitet, so würden wir damit auch eine viel genauere Vorstellung von dem Verlaufe der Nervenfasern innerhalb des Opticus erlangen, als wir bis jetzt besitzen, selbst wenn von den zur Section gekommenen Fällen keine oder nur ungenaue Gesichtsfeldaufnahmen ror- 
liegen sollten. Das Studium der Intoxicationsamblyopie verspricht uns demnach noch detaillirtere Aufschlïsse über die Lage der einzelnen Nervenfaserbündel innerhalb des Sehnerven zu geben, als wir ihm bisher schon verdanken.

Zum Schlusse meiner Arbeit ist es mir eine angenehme Pflicht, Herrn Geheimrath Förster für die durch Ueberlassung und Beschaffung des Krankenmateriales in reichlichster Weise zu Theil gewordene Unterstützung, sowio Herrn Dr. Baer für die freundliche Ueberlassung seiner Notizen und Krankengeschichten meinen besten Dank auszusprechen.

Verzeichniss der zu den Gesichtsfeldzeichnungen gehörigen Krankengeschichten.

(Fig. 1-30 zeigen nur den mittleren Theil des Förster'schen Gesichtsfeldschemas bis zum 40. Parallelkreise.)

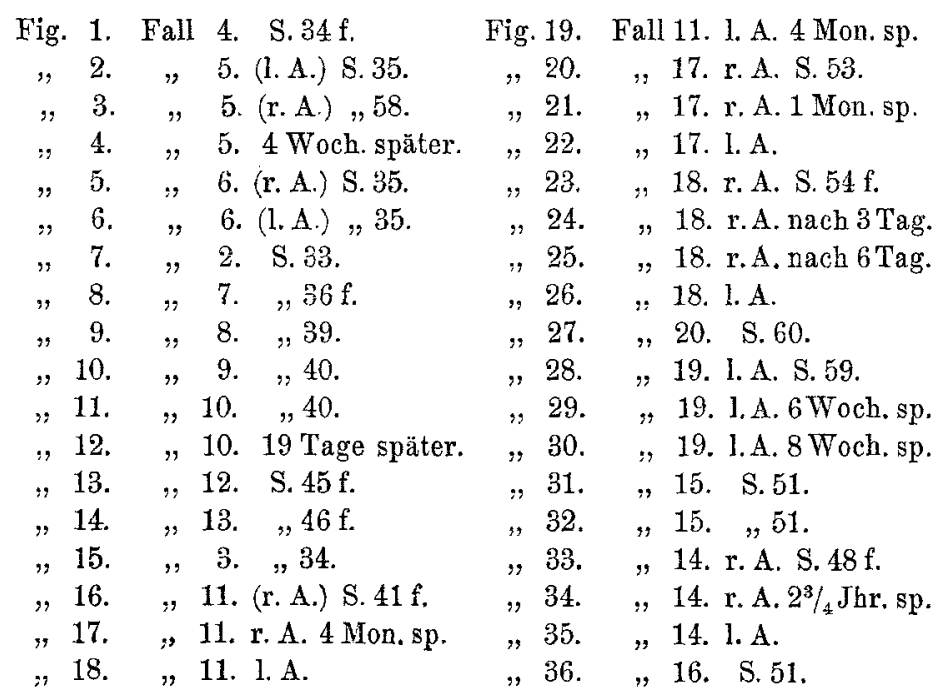




\section{Litteratur.}

1863 Sichel, Amales d'oculistique.

1864 Hutchinson, London. Hosp. Rep. I. S. 33.

1865 v. Graefe, Zehender's Klin. Monatsbl. f. A. III. S. 193. Sichel, Annales d'oculistique. LiII. S. 122-136.

Loureiro, Zehender's Klinisch. Monatsbl. f. A. III.

S. $394-396$.

1867 Erismann, Ueber Intoxicationsamblyopie. Dissert. Zürich. Hutchinson, Med. chir. transact. L.

Med. Times a. Gaz. Dec. 7 .

Thilesen, Nork's Magaz. XXI, 3.

Viardin, Bull. de Thér. LXXII. S. 141.

1868 Förster, Jahresbericht der schles. Gesellschaft. Annales d'oculistique. 1865 . S. 5.

1869 Th. Leber, Arch. f. Ophthalm. XV, 3. S. 60 und S. $236-247$.

Daguenet, Annales d'oculistique. LXII. S. 136-142.

1870 Talko, Warschauer Klinika. Nrr. 14.

Kosminski, ibidem. VIII. S. 12.

Reymond, Osservatore. Nr. 20.

1871 Hutchinson, Oplth. Hosp. Rep. VII, 2. S. 169-185. Hirschler, Graefe's Archiv. XVII, 1. S. 221-236. Förster, Klin. Monatsbl. f. A. IX. S. 344.

Galezowski, Gaz. des Hôp. S. 425, 429.

Leber, Arch. f. Ophth. XVII, 2. S. 283 (Anmerkung). Landolt, Annali d'Ottalm. S. 465 .

1872 Apostoli, Journ. d'Ophthalm. I, 9.

De neffe, Presse méd. belge. Nr. 31.

1873 Ponti, Annali di Ottalm. III. S. 107.

Rava, ibid, III. S. 92.

1874 Turnbull, Philad. med. Rep. Dec. 19.

Drysdale, Med. Press and Circular. May 6.

Hutchinson, Ophth. Hosp. Rep. VIII, 1. S. 4-5.

Magnan, De l'alcoolisme. Paris.

Schön, Die Lehre vom Gesichtsfelde. Berlin. S. 116 .

Chisholm, Ann. d'ocul. 71. S. 99.

Fumagalli, Ann. di Ottalm. III. S. 201-208.

1875 Treitel, Dissertation Königsberg. Ueber das Verhalten der periphereu und centralen Farbenperception bei Atrophia nervi optici.

Bull, New York medical Journ. Sept. S. 247. 
1875 Dickinson, The Saint Louis medical and surgical Journal. Jan. S. 25 , Febr. S. 57.

1876 Hutchinson, Ophth. Hosp. Rep. VIII. 3.

Linzbach, Ueber Scotoma centrale. Dissert. Bonn.

Krenchel, Amblyopia centralis. Kopenhagen.

Galezowski, Recueil d'Ophth. S. 210 and 331.

Förster, Handbuch von Graefe und Saemisch. Bd. VII. S. 201.

1877 Leber, Handbuch von Graefe und Saemisch. Bd. V. S. 829 und 880 .

Galezowski, Récueil d'ophthalm. S. 1 und 357.

Despagnet, Mourement médical. No. 27.

Guillot, Progrès medical. Juin.

Dolan, Med. Press and Circular. June.

Corso, Gaz. med. ital. lombard. Nr. 9.

Simons, Weekbl. van het Nederl. Tijdschr. von Geneesk.

16. S. 233.

Dornblüth, Volkmanns Sammlung, No. 122.

Stolt onhoff, Ueber Amblyopia nicotiana. Dissertation. Bonn.

Valzah, Philadelph. med. Times. S. 271.

1878 Baer, Ueber Gesichtsfeldmessung. Volkmann's Sammlung. Nr. 246.

Mahiels, Arch. méd. belg. Nov.

Hirschberg, Deutsche Zeitschrift für practische Medicin. Nr. 17 und 18.

L. Claren, Ueber Tabaksamblyopie. Dissertation. Bonn.

Chisolm, North. Car. med. Journ. Wilmington. II. S. 369.

Pötschke, Beiträge zur Diagnostik und Prognostik der Amblyopien. Dissertat. Berlin.

1878 Horner, Ueber Intoxicationsamblyopien. Correspondenz-

bl. f. Schweizer Aerzte. Nr. 13.

Martin, De l'arnblyopie nicotinique, Thèse de Paris.

Nuel. Annal. d'ocul. LXXX. S. 105.

1879 Reymond, L'Osservatore. Nr. 20.

Cohn, CentralbI. f. Augenheilk. S. 300 .

Alexander, Med. and surg. Report. Philad. XII. S. 469.

Calhoun, South. med. Record. Atlanta. IX. S. 321.

Coursserant, Journ. de conn. med. pract. Paris. I. S. 239.

Hirschberg, Brit. med. Journ. Aug. S. 321.

Lasègue, Arch. gén. de méd. CXIV. S. 342. 
1879 Galezowsiri, Récueil d'Ophth. S. 697.

1880 Nelson, Brit. mod. Journ, II. S. 774.

Webster, Med. Rec. New York. S. 649 and 665.

Fano, Journ. d'ocul, et de chirurg. S. 231.

Ely, New-York. med. Journ. XXXI. S. 397.

Berry, Georg. Ophth. hosp. Rep. X, 1. S. 44.

Secondi, R. Giorn. internaz. delle scienze med, S. 1128.

1881 Dehenne and Bonnefé. Rev. de thérap. méd. chir.

Paris. XLVIII. S. 203 u. 230.

Romiée, Recueil d'Ophth. S. 33.

Salm, Texas Med, and Surg. Rec. I. S. 305.

Sewny, Med. Rec. New-York. S. 329.

1882 Samelsohn, Arch. f. Ophth. 28, 1.

Nettleship, Transact. of the Ophthal. Societ. Vol.I.

Vossius, Areh. f. Ophth. 28, 3.

Shorten Krondhjem, Recueil d'Ophth. S. 210.

Ayres, S. C., Cincinnati Lancet and Clinic. Febr.

Segura, Clinica de Malaga. S. 119.

Fano, Journal d'Ocul. S. 193.

Petrucco, Gazz. med. ital. Prov. venete. Padova. Nr. 24 and 26.

Minor, J. L., Amer. Journ. of the med. sciences. April.

1883 Buzzard, T., Lancet. II. S. 52.

Priestley Smith, British med. Journ. I. S. 720.

Guelliot, Gaz. med. de l'Algérie. 28. S. 27.

Vossius, Klin. Monatsbl. f. Augenbeilk. S. 291.

Levinstein, Sehstörungen in Folge chronischen Gebrauches von Chloral, Morphium u. Nicotin. Dissert. Berlin.

Dapid, H., Dissertation. Paris. Essai sur les alterations fonctionelles et organiques de l'appareil de la vision survenant sous l'influence combinée de l'alcool et du tabac.

Ole Bull, v. Graefe's Archiv. XXIX, 3.

Dreier-Dufer, Gaz. méd. Algérie. Jan. et Fevr.

Galezowski, Recueil d'Ophth. S. 677.

Borthen, L., Norsk Magaz. for Laegevid. Band 12. S. $837-844$.

1884 Bunge, Ueber Gesichtsfeld und Faserverlauf im optischen Leitungsapparat. Halle.

Hutchinson, J., Medic. Tim. and Gaz. I. S. 40 .

Uhth off, Berliner klin. Wochenschrift. Nr. 25.

Moeli, Charité Annalen. IX. S. 524. 
1884 Berry, Ophth. Review. III. S. 101.

Galezowski, Annal. d'hygiène publique et de méd. légale. Jan. S. 47.

Shears, Brit. med. Journ. I. S. 1199.

Tobacco and Eyesight, Brit. med. Journ. I. S. 1264.

Panas, Union méd. XXXVII. S. 657.

1885 Filehne, Arch. f. Ophthalm. 31, 2. S. 1.

Ayres, S. C., Americ. Journ. of Ophth. II. S. 91.

Rampoldi, Annali di Ottalm. 14. S. 113.

Della amblyopia nicotinica. Pavia.

Pantoppidan, Hosp. tid. S. 709.

Cheatam, W., Americ. Journ. of Ophth. S. 102.

Coleman, W. F., Maryland med. Journ. Balt. XII. S. 371.

- Chicago med. Journ. Exam. LI. S. 216.

Coursserant, Archiv d'Ophth. S. 179.

Gaz. des hôpit. No. 20.

Schwarzbach, B., Australas. med. Gaz. IV. Nr. 5. S.127.

1886 Pötschke, Dissertat. Dorpat.

Uhthoff, Arch. f. Ophth. 32, 4. S. 95 und 33, 1, S. 257.

Bergmeister, Ueber Intoxicationsamblyopie, Wiener medicinische Presse. Nr. 8. S. 139.

De Schweiuitz, Med. News. XLIX. S. 550.

Damont, Bullet. clin. mat. opht. de l'bosp. d. Quinze Vingts. IV. S. 79, 140 und 142.

Gand, ibidem. S. 68 .

Nettleship, Ophth. Hosp. Reports. XI. S. 70 u. 72.

Hartridge, G., Brit. med. Journ. I. S. 200.

Hutchins on, Jon., Ophth. Hosp. Reports. XI, 2. S. 188.

Minor, J. L., Americ. Jouru. of Ophth. III. S. 26.

Standish, Boston med. and surgic. Journ. April 22.

1887 Alt, A., New Yorker med. Presse. IV. S. 13.

Armaignac, Revue clin. d'Oculist. Mars. S. 55.

Bendell, H., Albany med. Ann. VIII. S. 169.

Chisolm, Americ. Journ. of Ophth. S. 68.

Howe, Transact. South. Car. med. assoc. Charleston. S. 103.

Nettleship, Ophth. Reriew. S. 227.

Brit. med. Journ. II. S. 21.

Ray, J. M., South-West med. Gaz. Louisville. I. S. 262.

Skinner, D. N., Fr. Maine med. ass. Portland. S. 247.

1888 Baker, A. R., Lancet-Clin. n. s. S. 711. 
Browne, E. A., Ophth. Reriew. S. 222.

- Liverpool med.-chirurg. Journ. VIII. S. 107.

Bruns, H. D., New Orleans med. and surgic. Journ. n. s. XVI. S. 110.

Buxton, A. St. C., Lancet. I. S. 367.

Doyne, R. W., Ophth. Hosp. Reports. XII. Part. I. S.51. Madon, Crón. med. quir. de la Habana. XIV. S, 375. Millingen, Ophth. Review. S. 63 .

Webster, D. A., New-York med. Journ. XLVIII. S. 256.

1889 Baker, A., Vortrag in der ophth. Section der Am, med.

Associat citirt nach Centralbl. f. Augenheilk. S. 88. Williams, St. Louis med, on surg. Journ. Nr. 6. S. 373. Branchli, Ueber durch Tabak und Aleohol verursachte Intoxicationsamblyopie. Dissert. Zürich. 

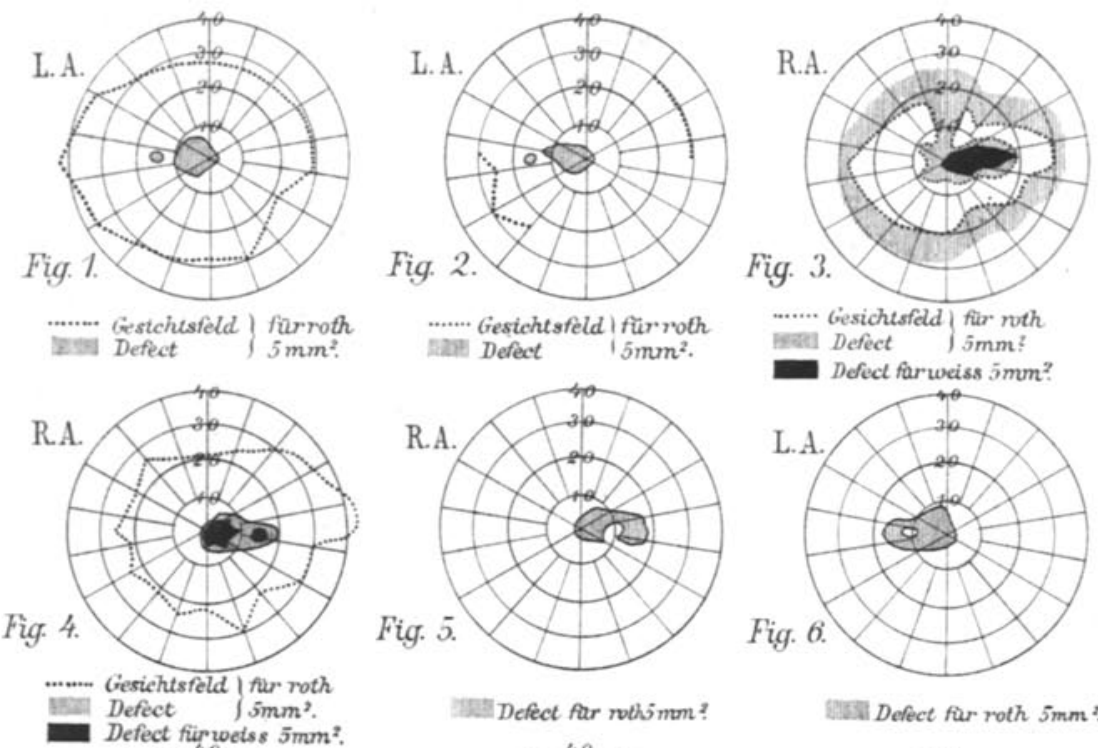

(10) Defect fur rothimm?

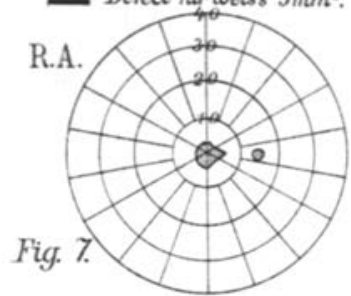

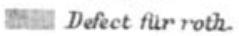

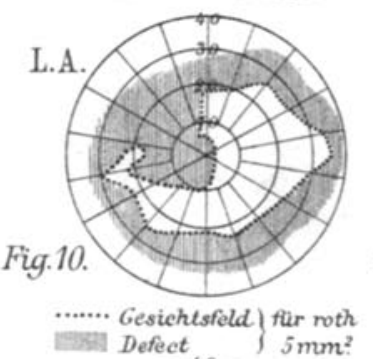

Fig. 8.

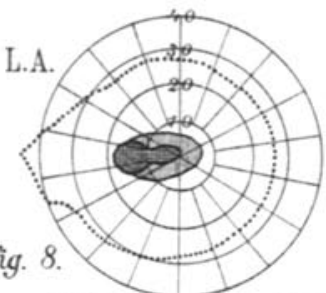

Defect für f Wiste am 24.5.77. roth $5 \mathrm{~mm}^{2}$ \{ IISOI am 27. 977 .

Fig. 9 .
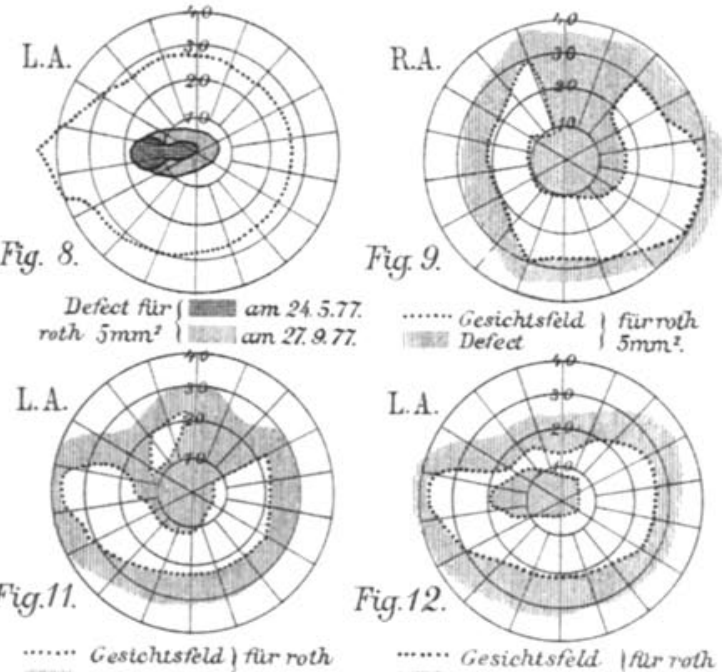

….. Gesichtsfeld ) fuir roth

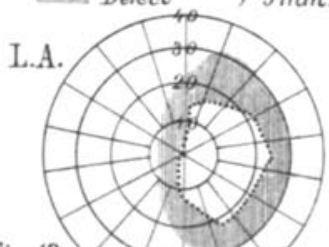

Fig. 13.

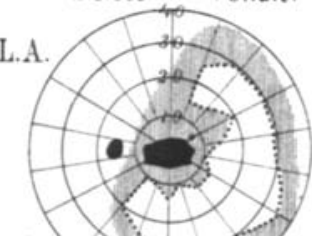

Fig. 14.

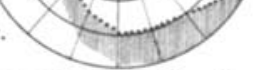

...... Gesichtsfeld ) für roth

...... Gesichtsfeld | fiur roth

Bater Dofect $10 \mathrm{~mm}^{2}$

Defect fir weiss $5 \mathrm{~mm}^{2}$ ? 

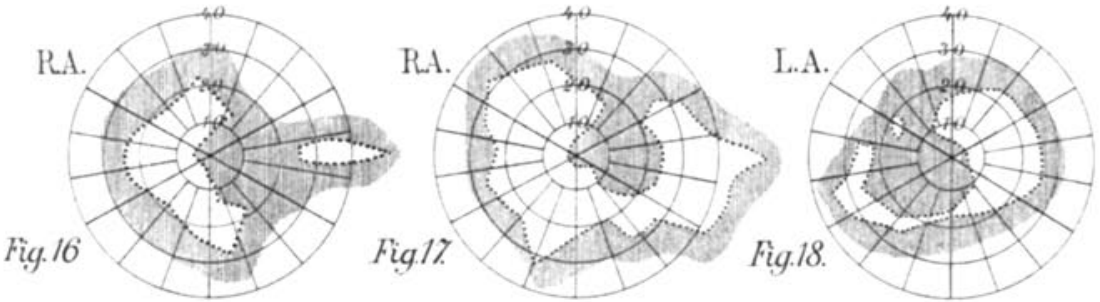

$$
\text { Gerichtsfeld flurroth } .3 \mathrm{~mm}^{2}
$$

was Defect fürroth $5 \mathrm{~mm}$,
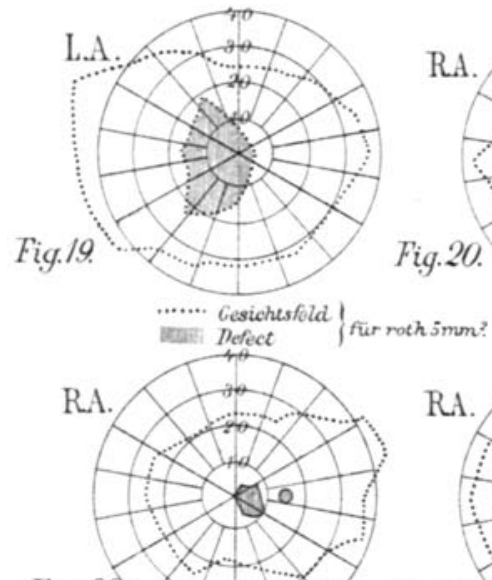

Fig. 22.

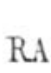

Fig 2.3.

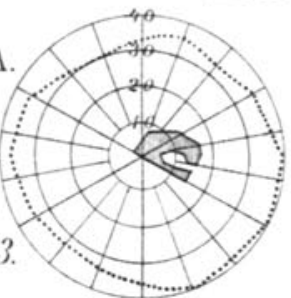

Fig. 2l.

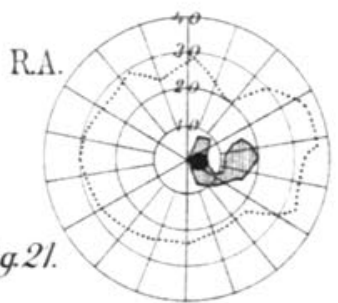

Defect firmeiss Jimm?

….. Gesichtsfeld fur roth $5 \mathrm{~mm}^{2}$

RA.

Fig.?4.

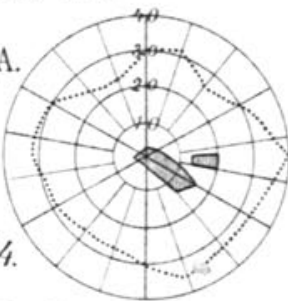

...... Gesichtsfeld | für roth

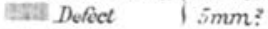

12: Defect fiur roth $2 \mathrm{~mm}$ ?
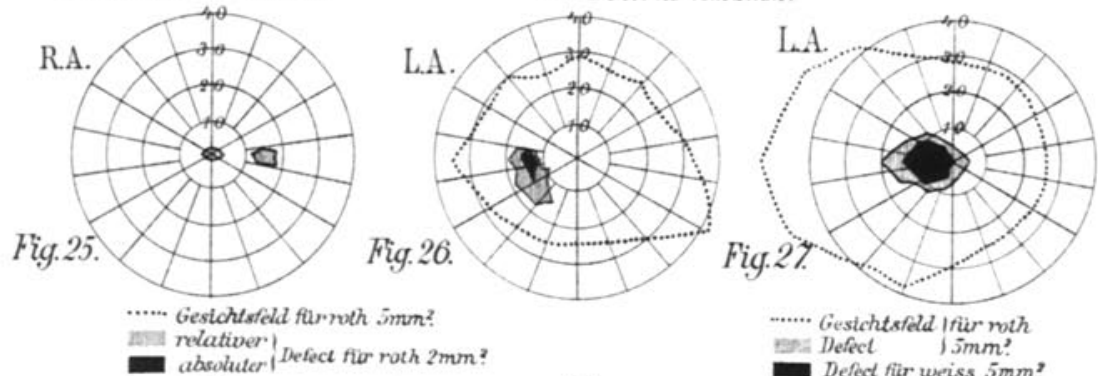

and relativer

- absoluter ' Defect filo roth $2 \mathrm{~mm}$ ?
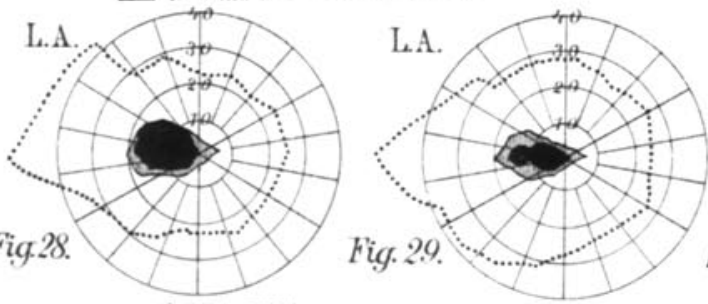

Fịg.28.

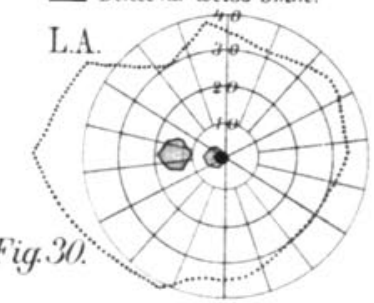

Fi.... liesichesfeld f fir roth $5 \mathrm{~mm}$ ?

Defect fïr weiss $5 \mathrm{~mm}$ ? 

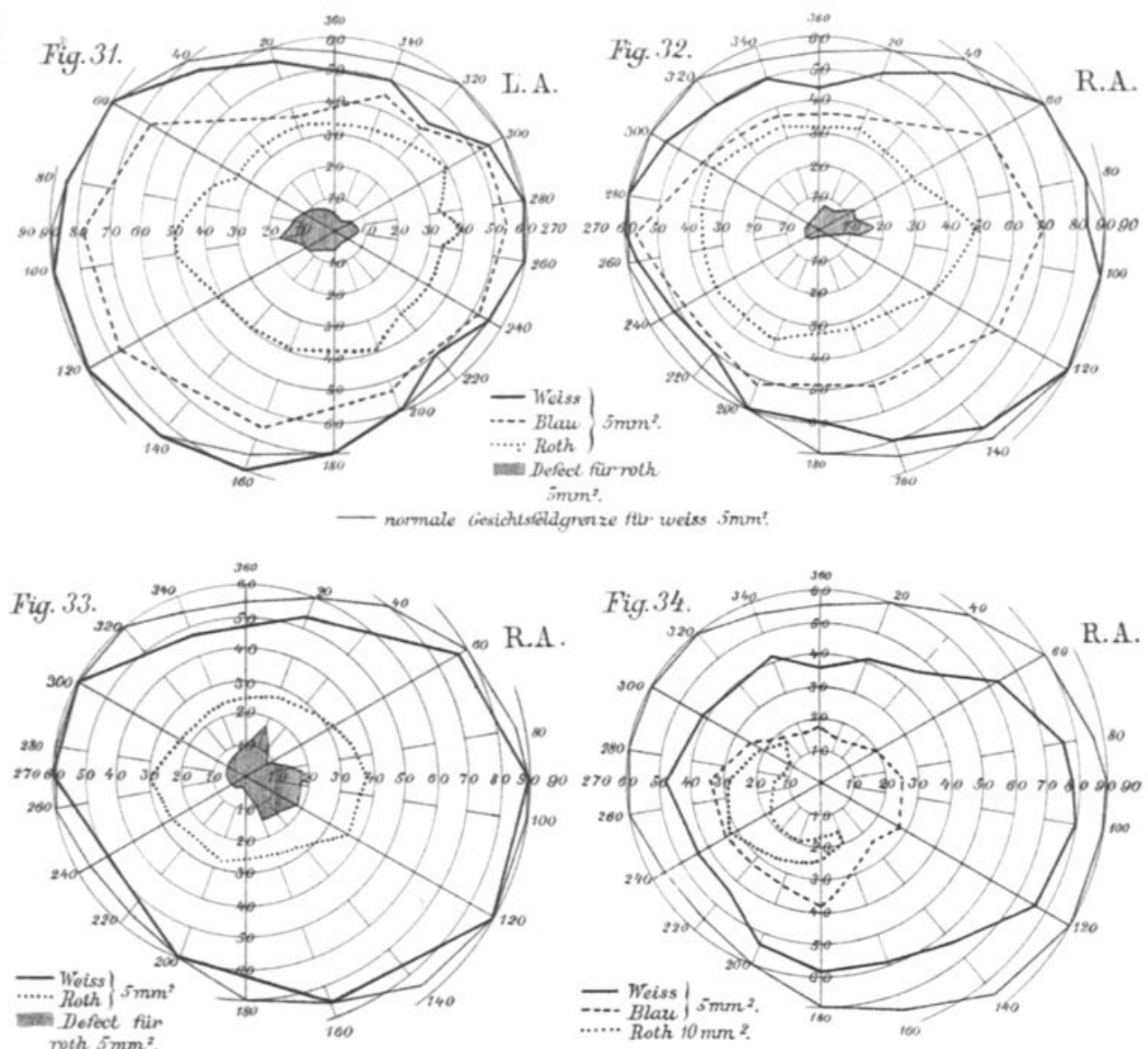

- normale Gesichtsfeldgrenze fïr weiss $5 \mathrm{~mm}$ ?
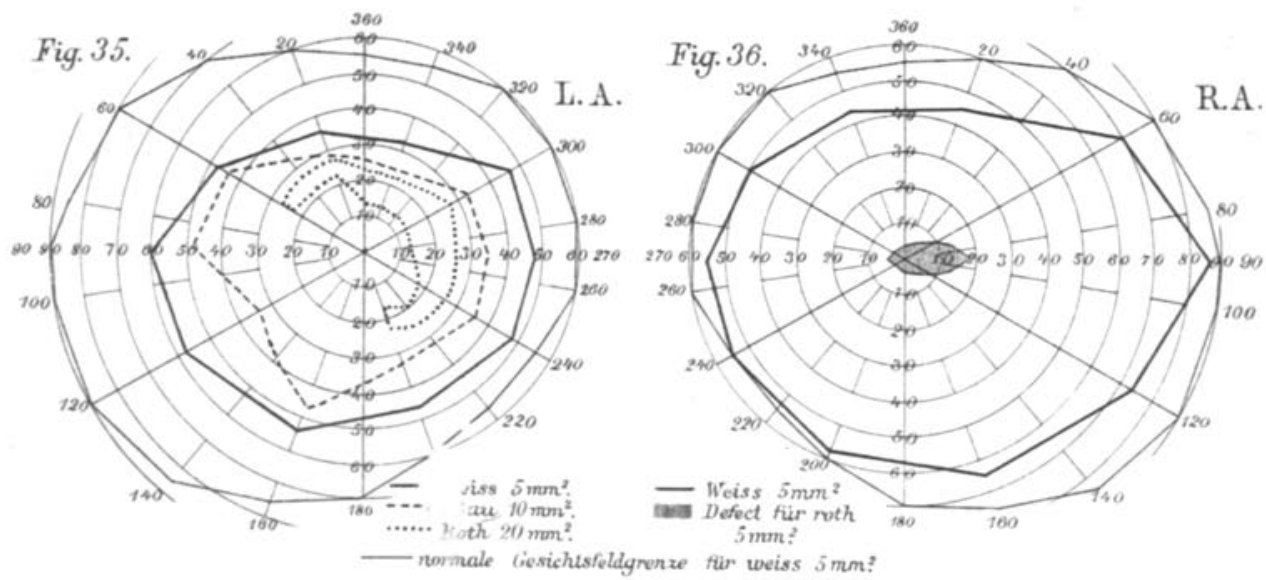